\title{
THESIS
}

\section{HUMAN RESPONSES TO SIMULATED MOTORIZED NOISE IN NATIONAL PARKS}

\author{
Submitted by \\ David Weinzimmer \\ Department of Human Dimensions of Natural Resources
}

In partial fulfillment of the requirements

For the Degree of Master of Science

Colorado State University

Fort Collins, Colorado

Summer 2013

Master's Committee:

Advisor: Peter Newman

Michael Manfredo

Paul Bell 
Copyright by David Weinzimmer 2013

All Rights Reserved 


\section{ABSTRACT}

\section{HUMAN RESPONSES TO SIMULATED MOTORIZED NOISE IN NATIONAL PARKS}

This thesis investigated the effects of three sources of motorized noise on laboratory participants’ evaluations of landscape scenes, self-reported affective states, and physiological responses in simulated national park settings. Seventy-seven laboratory participants completed landscape assessments along 8 aesthetic dimensions and reported affective states while listening to audio clips of natural sounds, propeller planes, motorcycles, and snowmobiles. Each participant experienced all scenes and sound conditions in a pseudo-randomized order. The change from the natural sound baseline for each motorized source of noise was calculated. Results indicated that all motorized sources of noise had detrimental impacts on landscape assessments and self-reported affective states, compared to natural sounds. Motorcycle noise was demonstrated to have the largest negative impact on landscape assessments. Physiological response was also affected by experimental noise in some of the conditions (with the strongest effect in the snowmobile condition), but a consistent pattern of results failed to emerge to suggest that negative impacts to human physiology could be reliably detected under the present methodology. In addition to confirming that noise from motorized recreation has significant social impacts on potential park visitors, this simulation suggests that the specific source of the noise is an important factor in observer evaluations. These results could help park managers prioritize their educational and regulatory strategies for minimizing adverse impacts by motorized vehicles on natural soundscapes. Important advances in soundscape research methodology are also presented. 


\section{TABLE OF CONTENTS}

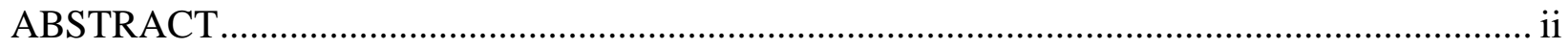

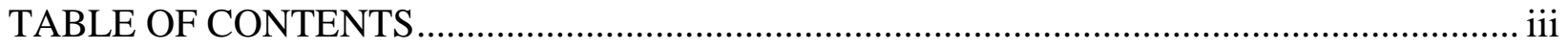

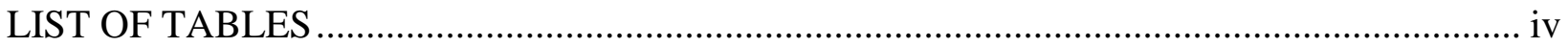

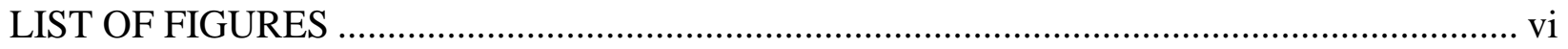

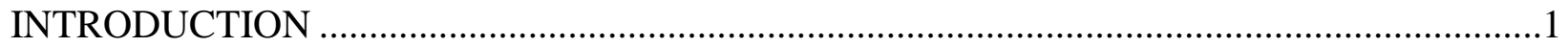

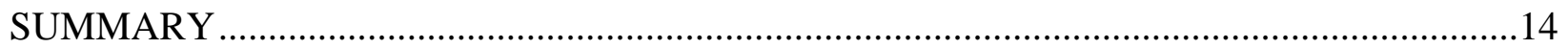

CHAPTER 1. DIFFERENCES IN LANDSCAPE ASSESSMENT IN RESPONSE TO MOTORIZED AND NATURAL SOURCES OF SOUND ….............................................19

CHAPTER 2. CHANGES IN SELF-REPORTED AFFECT IN RESPONSE TO MOTORIZED

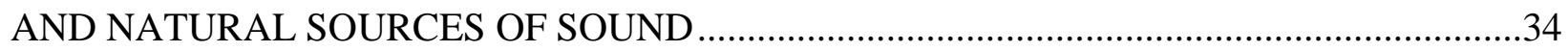

CHAPTER 3. PHYSIOLOGICAL RESPONSE TO MOTORIZED AND NATURAL SOURCES

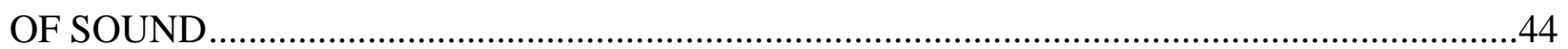

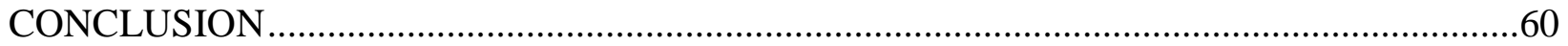

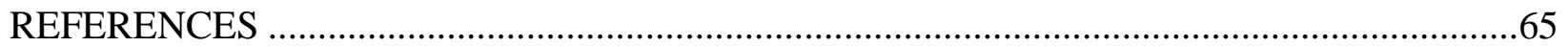

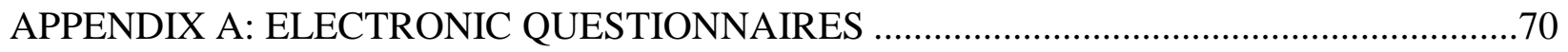




\section{LIST OF TABLES}

Table 1 . Reliability analysis for landscape assessment composite natural variables .25

Table 2. Reliability analysis for landscape assessment composite motorized variables .26

Table 3. Descriptive statistics for landscape assessment composite variables .27

Table 4. Descriptive statistics for landscape assessment difference scores..... .28

Table 5. Paired samples $t$-test between landscape assessment natural and motorized conditions

Table 6. Tests of within-subjects effects from landscape assessment repeated measures ANOVA

Table 7. Means (standard deviations), percent reductions, and pair-wise comparisons between landscape assessment difference scores

Table 8. Comparison of landscape assessment sound condition order effects using one-way ANOVA

Table 9. Means (standard deviations), percent reductions, and pair-wise comparisons between PANAS1 and PANAS2.

Table 10. Means (standard deviations), percent reductions, and pair-wise comparisons between

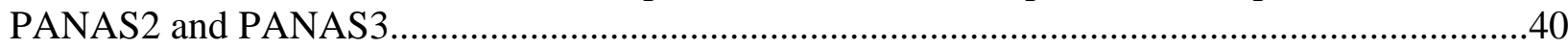

Table 11. Summary physiological data for baseline and sound conditions ...............................51

Table 12. Percent change physiological data for baseline and sound conditions

Table 13. Paired samples $t$-tests between baseline and combined natural and motorized sound conditions for GSR

Table 14. Paired samples $t$-tests between baseline and combined natural and motorized sound conditions for HR.

Table 15. Paired samples $t$-tests between natural and motorized conditions for GSR . .53

Table 16. Paired samples $t$-tests between natural and motorized conditions for HR .53

Table 17. Significant correlations between GSR and PANAS ....... .54

Table 18. Significant correlations between HR and PANAS ..... .55 
Table 19. Significant correlations between physiological data and psychological scales............56

Table 20. Significant correlations between physiological data and landscape assessments..........57 


\section{LIST OF FIGURES}

Figure 1. Reaction model for hypothesis testing in epidemiological noise research....................6

Figure 2. Model of noise perception and psychophysiological effects of noise, risk factors, and

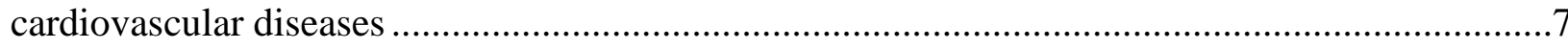

Figure 3. Conceptual model of soundscapes using systems approach....................................9

Figure 4. Psychophysiological stress model according to Henry (1992)..................................12

Figure 5. Overview of study design and timeline of experimental procedures ..........................21

Figure 6. Change in positive and negative affect from PANAS1 to PANAS2 following each

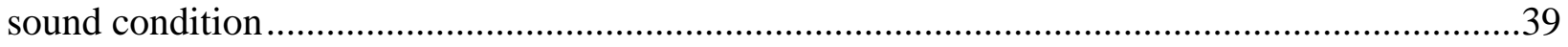

Figure 7. Change in positive and negative affect from PANAS2 to PANAS3 following each

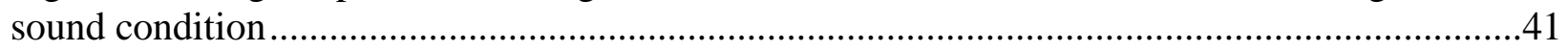

Figure A-1. Baseline, psychological, and demographic questionnaires ..................................71

Figure A-2. Landscape assessment and attitude questionnaires ...........................................82 


\section{INTRODUCTION}

For as long as parks and protected areas have existed, people have looked to them for a variety of individual and societal benefits. Some people want clean air and water; others value the opportunity to view landscapes and wildlife in natural settings. For many, the allure is for primitive forms of recreation and physical challenge that do not exist elsewhere. And as cities get more crowded, suburbs expand into the countryside, and roads become more congested, the benefits that parks offer become increasingly valuable to the public. In fact, Driver (2008) lists over 150 potential benefits of outdoor recreation - grouped as personal, social/cultural, economic, and environmental - that have some empirical documentation. Parks and protected areas provide a particularly high concentration of these benefits, many of which are unique to these areas. Our parks and forests and wilderness areas provide the nation's healthiest ecosystems, best wildlife habitat, wildest rivers, and tallest mountains. And, perhaps even more importantly, they offer our best opportunities to unwind after a stressful week, reconnect with friends and family, and interact intimately with nature. As Wagar (1966) once wrote, “The sole purpose of all land management is to provide benefits for people” (p. 9). In our increasingly crowded and hectic world, one way that protected areas can provide significant benefits for all to enjoy is through the conservation of opportunities to experience natural sounds.

\section{The Need for Benefits}

Almost 150 years ago, Frederick Law Olmsted recognized the value of nature in supporting psychological well-being: “[Viewing nature] employs the mind without fatigue and yet exercises it; tranquilizes it and yet enlivens it; and thus, through the influence of the mind over the body, gives the effect of refreshing rest and reinvigoration to the whole system” (Olmsted, 1865). Olmsted's words may be even more appropriate today, as contact with nature 
has repeatedly proven to be a critical factor in healthy human development. As our society becomes increasingly technological and urbanized, and thus, less directly connected to nature, we are beginning to see negative impacts on public health (increased rates of childhood obesity and psychological disorders, for example). The children and nature movement is a direct response to the disconnection of children from the benefits of nature. Children suffering from what Richard Louv termed "nature-deficit disorder” (Louv, 1995) are missing out on important opportunities to develop skills and knowledge that nature experiences can provide. Taylor and Kuo (2006) review several of the studies linking nature experiences to positive outcomes in child development, including increased self-esteem, self-confidence, interpersonal skills, and school performance, and decreased frequency of conduct disorders, anxiety, and depression. Clearly, protection of the multi-dimensional benefits offered by our protected natural areas should remain a critical priority for land managers, specifically, and the public, more generally.

\section{Managing for Benefits}

For several decades, federal land management agencies have focused recreation management approaches on potential benefits for the public. Rather than looking only at the supply and demand of recreation as measures of quality, as had been done in the past, a new approach evolved in the 1970s that considered broader benefits - both individual and societal to be the goal of recreation experiences provided for by the agencies. From this change in approach came influential new tools for recreation management centered on understanding the motivations that people bring with them to their recreation experiences, and how management can best accommodate those desires. The tools that emerged were experience-based management (Manfredo, Driver, \& Brown, 1983) and its offshoot, benefits-based management (Lee \& Driver, 1992). Both of these paradigms draw on the psychological concept of 
expectancy-valence theory (Lawler, 1973), in which expectations about the outcome of an activity, and how the activity is subsequently evaluated, directly define feelings of satisfaction.

Recreationists’ motivations for desired psychological outcomes (whether it be solitude, family bonding, or connecting with nature) determine their participation in, and, ultimately, satisfaction with, their recreation experiences. Managers should aim to provide a range of activity types and setting attributes (resource, social, and managerial) to address the diversity of experiences and psychological outcomes desired by visitors (Driver, Brown, Stankey, \& Gregoire, 1987). Thus, if people visit a protected area motivated by the expectation to experience natural sounds and to recuperate from a stressful week, then the presence of excessive, unnatural noise will likely leave them dissatisfied with their experience. We know that many visitors share these motivations to escape the noise and commotion of their everyday lives in their outdoor recreation experiences (Driver, Nash, \& Haas, 1987).

\section{Natural Soundscapes}

Of all of the benefits offered by protected areas, one of the most frequently cited and sought after by visitors is the opportunity to experience natural quiet and the sounds of nature. Over $90 \%$ of visitors mention the enjoyment of natural quiet and the sounds of nature as primary motivators for visiting national parks (McDonald, Baumgartner, \& Iachan, 1995). The typical visitor wants to hear birds singing, wind rustling leaves, and water cascading down a creek - not people talking on cell phones, car horns, and dogs barking. This overwhelming desire of the general public to escape the stress of everyday life by visiting a protected area is a driving force behind the growing realization by natural resource managers that natural soundscapes (the human perception of acoustical environments) need to be protected like any other valuable natural resource. A growing body of research also documents the clear biological and behavioral 
impacts of anthropogenic noise on a variety of wildlife. Winter snowmobile use and vehicle traffic in Yellowstone (Creel et al., 2002) and scenic aircraft overflights (Pepper, Nascarella, \& Kendall, 2003) have been specifically implicated in detrimental physiological effects on wildlife. And although direct effects on humans and animals were not analyzed at the time, frequent, high levels of noise from motorcycles have been documented at the Blue Ridge Parkway (National Park Service, 2011).

\section{Soundscape Policy in the National Park Service}

The National Parks Overflights Act of 1987 was one of the first federal efforts to systematically protect natural soundscapes in public lands. This law also motivated new psychological research on the impacts of noise in protected areas (Gramann, 1999). Several important policies on soundscape protection followed. In response to the fact that its parks were rapidly become louder, in 2000 the National Park Service (NPS) issued Director’s Order \#47: Soundscape Preservation and Noise Management "to articulate National Park Service operational policies that will require, to the fullest extent practicable, the protection, maintenance, or restoration of the natural soundscape resource in a condition unimpaired by inappropriate or excessive noise sources” (NPS, 2000). The order established guidelines for monitoring and planning to preserve park soundscapes. The National Parks Air Tour Management Act of 2000 required the Federal Aviation Administration (FAA) to work with the NPS to address and mitigate adverse impacts of commercial air tours on NPS resources, including natural soundscapes. And in 2006, the NPS Management Policies included several directives related to soundscapes, including the affirmation that "The Service will preserve, to the greatest extent possible, the natural soundscapes of parks” (NPS, 2006). Controversies surrounding snowmobile use in Yellowstone, scenic air tours over the Grand Canyon, and 
personal watercraft use in multiple NPS units continued to highlight the growing threat of human-caused noise to the park experience, wildlife, and natural and cultural resources, as well as the potential for conflict between stakeholders.

As many NPS units are faced with environmental change, external factors that affect conditions, changing visitor use patterns, and intensity of uses, it becomes increasingly challenging to provide continued recreational activities and experiences that are mandated through NPS policies. These mandates require that NPS units protect the acoustic environment, just as they strive to preserve other resource and social conditions. Therefore, park managers need information concerning visitor experiences and preferences associated with the park soundscape. By better understanding the nature of acoustic impacts that may affect resource and social conditions within their park boundaries, managers can make informed decisions about how to preserve natural soundscapes and meet expectations of visitors (Taff, 2012).

\section{Dangers of Excessive Environmental Noise}

Excessive environmental noise poses distinct threats to human and animal well-being. For humans, there are general dangers in both physical and psychological dimensions, which are often highly interrelated. High levels and durations of noise events have been associated with cardiovascular problems, elevated levels of stress, decreased immune function, and impairments

of cognition. Aydin and Kaltenbach (2007) found an increase in objective circulatory parameters (i.e., hypertension) and subjective factors (i.e., annoyance) in areas exposed to high levels of airport noise. Babisch, Fromme, Beyer, and Ising (2001) studied traffic noise exposure and stress hormones and reported increased endocrine response to high levels of environmental noise. The authors' model of the relationships between noise, biological response, and health outcome is displayed in Figure 1. Ising and Krupp (2004) present a similar model (Figure 2), 
with greater attention to the mediating parameters that influence the physical and psychological outcomes of noise exposure. Babisch et al. (2001) also implicated coping mechanisms and control over the stimulus as moderating factors in physiological responses to noise. This is one reason why children may be more vulnerable to the detrimental effects of noise, as they tend to lack control over their surroundings and the ability to escape their environment if noise is excessive (Cohen, Evans, Krantz, \& Stokols, 1980). This combination of psychological risk factors is also implicated in the development of feelings of helplessness, which in turn can lead to illness and depression (Seligman, 1975).

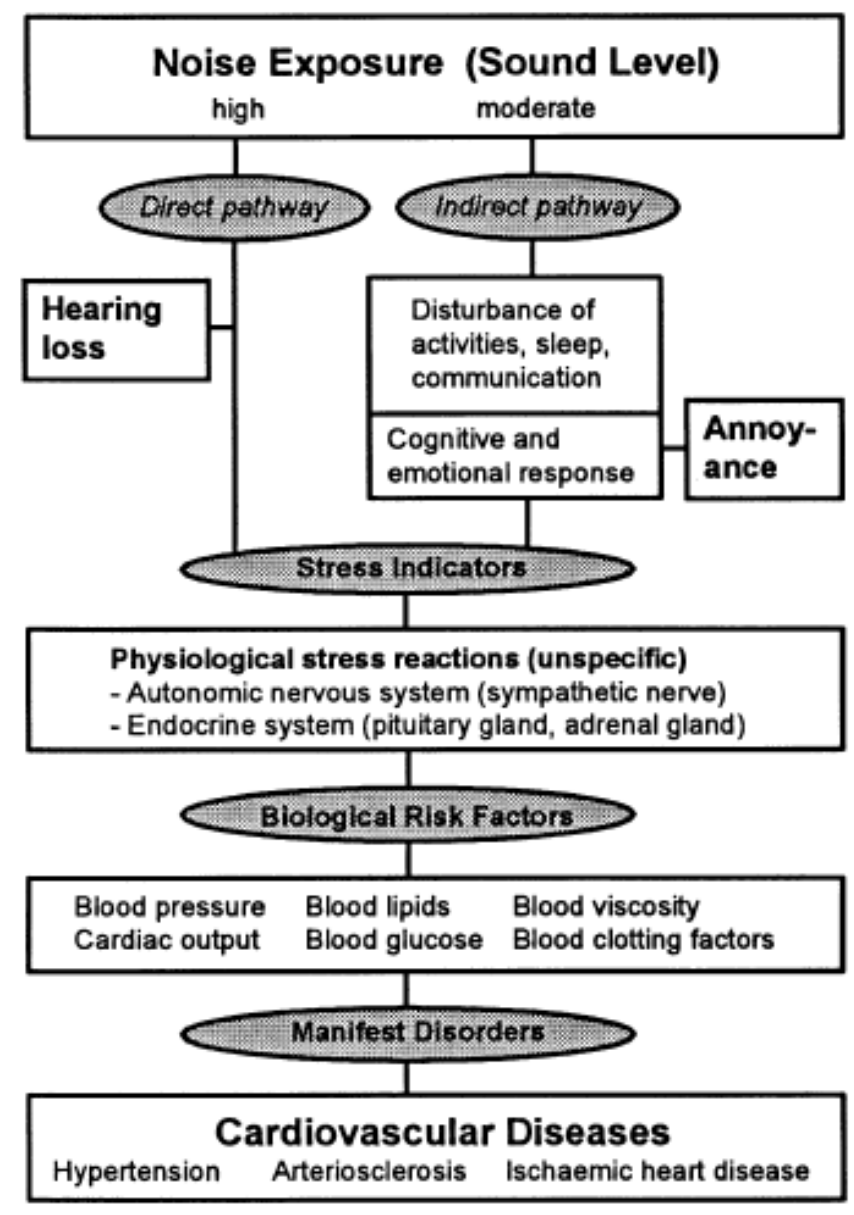

Figure 1. Reaction model for hypothesis testing in epidemiological noise research. Adapted from Babisch et al. (2001). 


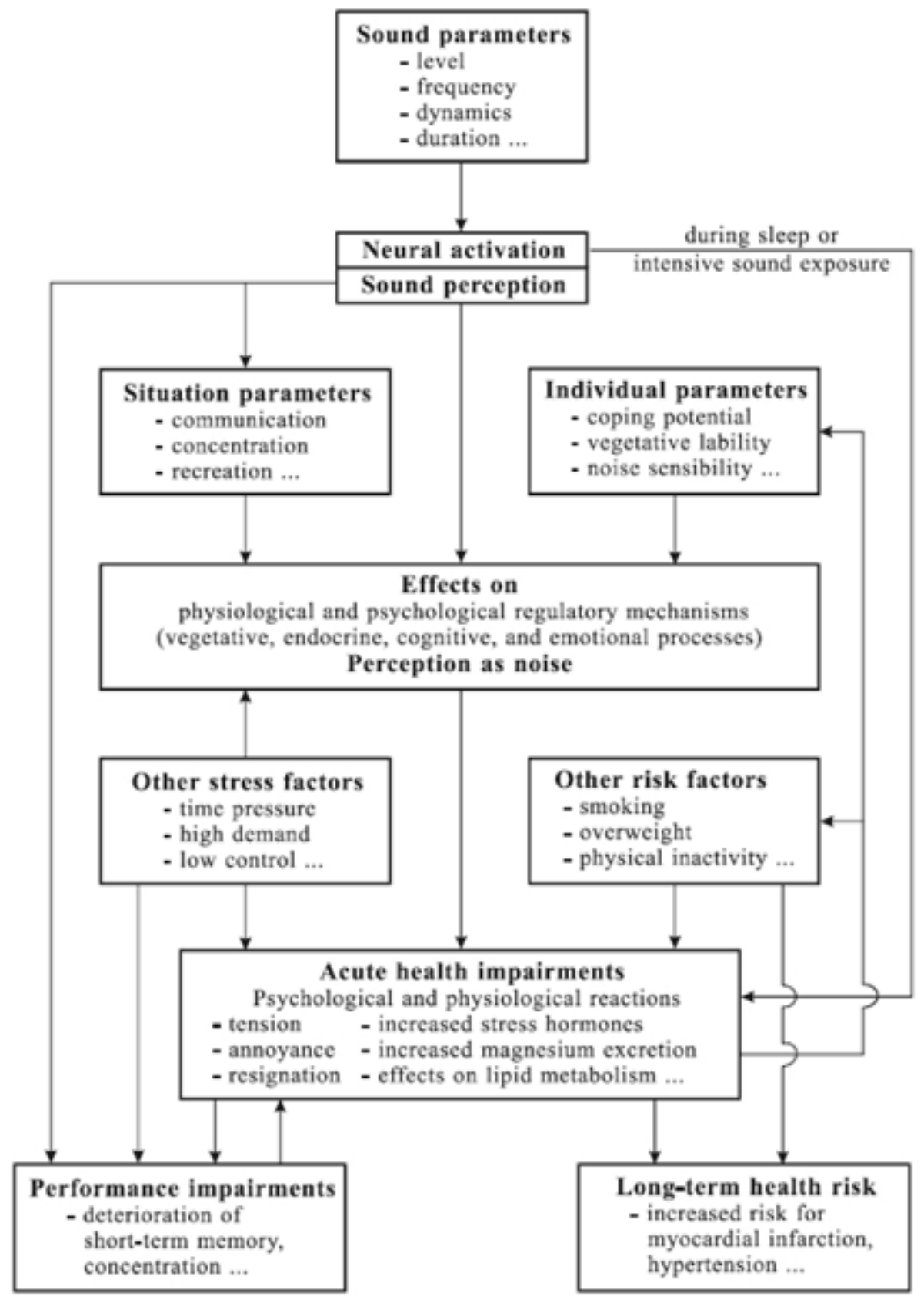

Figure 2. Model of noise perception and psychophysiological effects of noise, risk factors, and cardiovascular diseases. Adapted from Ising \& Krupp (2004).

Evans, Bullinger, and Hygge (1998) combined longitudinal physiological and quality of

life measurements to demonstrate a detrimental and enduring effect of airport noise on health and well-being. Staples (1996) identified a list of cognitive variables that are sensitive to disruption by chronic levels of environmental noise, including decreased school performance and learning 
ability in children, decreased tolerance for frustration, and fewer instances of helping behavior. Staples (1996) emphasized the importance of subjective responses to noise as more predictive of adverse reactions to noise than the physical acoustic properties alone. She also underscored the application of environmental stress theory to noise exposure. Environmental stress theory identifies two critical factors in predicting adverse reactions to noise: 1) appraisal of the event as threatening important personal needs or goals, and 2) subjective lack of control over one's exposure. Individual reactions to noise will be influenced by these factors, leading to varying degrees of psychological distress, physical symptoms, and annoyance.

\section{Impacts of Noise on Visitor Experiences in Protected Areas}

Visitor experiences. In addition to threats to physical and psychological health, there are specific threats from anthropogenic noise to the quality of outdoor recreation experiences in protected areas. As stated above, many visitors are motivated to hear natural sounds and experience the quiet solitude of protected areas. If the ambient levels of human-caused noise are too high (perhaps due to road traffic, motorized recreation, or park maintenance activities), then natural sounds are likely to be missed. This is a lost opportunity to provide a real and valuable benefit to the public. The concerted protection of natural soundscapes in our protected areas will create refuges from the acoustic overstimulation that characterizes urban life. People need places to escape to where they can have restorative experiences, clear their heads, and improve their mood. It is imperative for their satisfaction with their recreation experience, as well as their physical, affective, and psychological well-being. A conceptual model of soundscapes and visitor satisfaction using a systems approach developed by Newman, Manning, and Trevino (2010) is shown in Figure 3. 


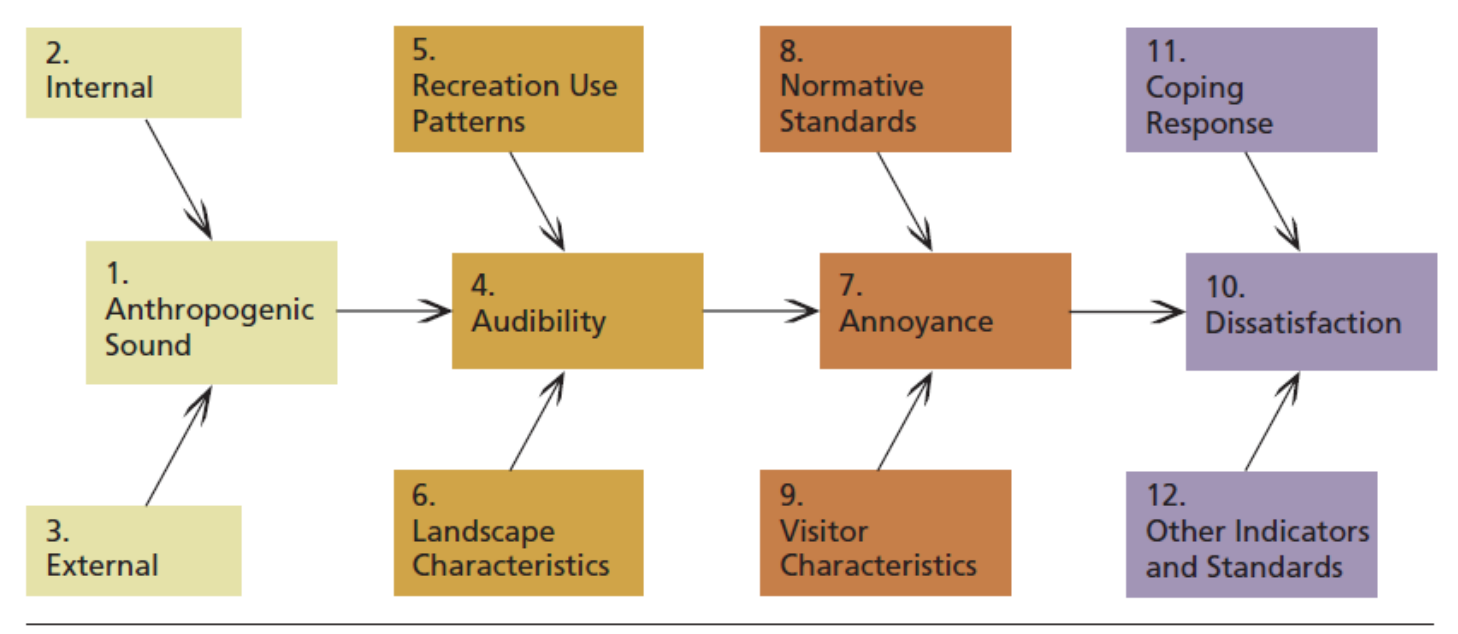

Figure 3. Conceptual model of soundscapes using systems approach. Adapted from Newman, Manning, \& Trevino (2010).

Wildlife impacts. Similarly, animals are impacted by unnatural noise intruding on their habitats. Anthropogenic noise can alter their foraging behaviors (Quinn, Whittingham, Butler, \& Cresswell, 2006), reproductive success (Habib, Bayne, \& Boutin, 2007), stress hormone levels (Owen, Swaisgood, Czekala, Steinman, \& Lindburg, 2004), and ability to defend themselves from predators (Rabin, Coss, \& Owings, 2006). Hearing is a critical sense to many wildlife species, and high levels of noise can lead to a "masking” effect that interferes with their ability to make full use of this sense (just as the presence of anthropogenic noise can interfere with humans' ability to experience and enjoy the sounds of nature). Winter snowmobile use and vehicle traffic in Yellowstone (Creel et al., 2002) and scenic aircraft overflights (Pepper, Nascarella, \& Kendall, 2003) have been specifically implicated in detrimental physiological effects on wildlife. As the impacts of noise on wildlife aggregate, there is the danger of significant ecological adaptations, as well (Barber et al., 2010; Barber, Turina, \& Fristrup, 2010).

Anthropogenic noise leads to wildlife behavior that is unnatural - whether the animals learn to avoid the sources of noise or habituate to them. In either case, this disruption to natural patterns of behavior is in conflict with the NPS mission to "conserve the scenery and the natural 
and historic objects and the wild life therein and to provide for the enjoyment of the same in such manner and by such means as will leave them unimpaired for the enjoyment of future generation” (NPS, 1916). With any loss of naturalness in protected areas, there is a corresponding loss of opportunities for important human benefits, as naturalness is a quality that is highly valued by many visitors. Just like natural quiet and the sounds of nature, people are motivated by, value, and benefit from the ability to observe wildlife in their natural settings.

\section{Previous Soundscape Research}

Most previous human dimensions research on natural soundscapes in protected areas has depended on subjective self-report measures (see e.g., Pilcher, Newman, \& Manning, 2009; Stack, Newman, Manning, Aiken, \& Fristrup, 2011) and dose-response methodologies, in which listeners rate their reactions to various sound stimuli in order to measure standards of soundscape quality (Marin, Newman, Manning, Vaske, \& Stack, 2011). Cognitive factors, like motivations, attitudes, and subjective norms, and behavior can be studied by surveying park visitors about their expectations and experiences. Visitors are often asked about their levels of annoyance in response to a particular sound, how often they heard it, and how loud they considered it to be. In the laboratory, carefully designed sound clips can be played for participants in a controlled environment and ratings of different cognitive indicators obtained (e.g., annoyance, acceptability, tranquility, etc.). Experimenters can ask questions about stress, restoration, and affect, but this method is more indirect and subject to bias, so the external validity of these designs is likely to be lower. A potentially informative and exciting line of research would explore more biologically-based measures of the physical and psychological effects of natural and anthropogenic sounds. 


\section{New Directions in Soundscape Research}

Relatively simple technology exists to measure indicators of physiological arousal, including heart rate, blood pressure, and skin conductance (or electrodermal activity). These physiological indicators have well-established links to arousal of the autonomic nervous system that can be caused by stress and emotion. Henry’s (1992) psychophysiological stress model is shown in Figure 4, demonstrating potential pathways between stressful stimuli and physiological response. Stress hormones, like cortisol and catecholamines, biomarkers for endocrine functioning, can also be assayed by relatively simple procedures (sampling blood or saliva), in order to create a more complete picture of the stress response of the participant. Physiological and endocrine measures offer the possibility of obtaining more objective, sensitive, unbiased indicators of stress, restoration, and affect than can be provided by cognitive- and behavioralbased measurements that are currently the standard in the field. And due to the passive, continuous, and relatively non-invasive nature of these procedures, it is possible to obtain physiological and endocrine measurements at the same time that cognitive-based, self-report data are acquired. Thus, biologically-based techniques would allow researchers to add to the body of knowledge about natural soundscapes in protected areas, while also validating existing results and theories based on cognitive and behavioral data. 


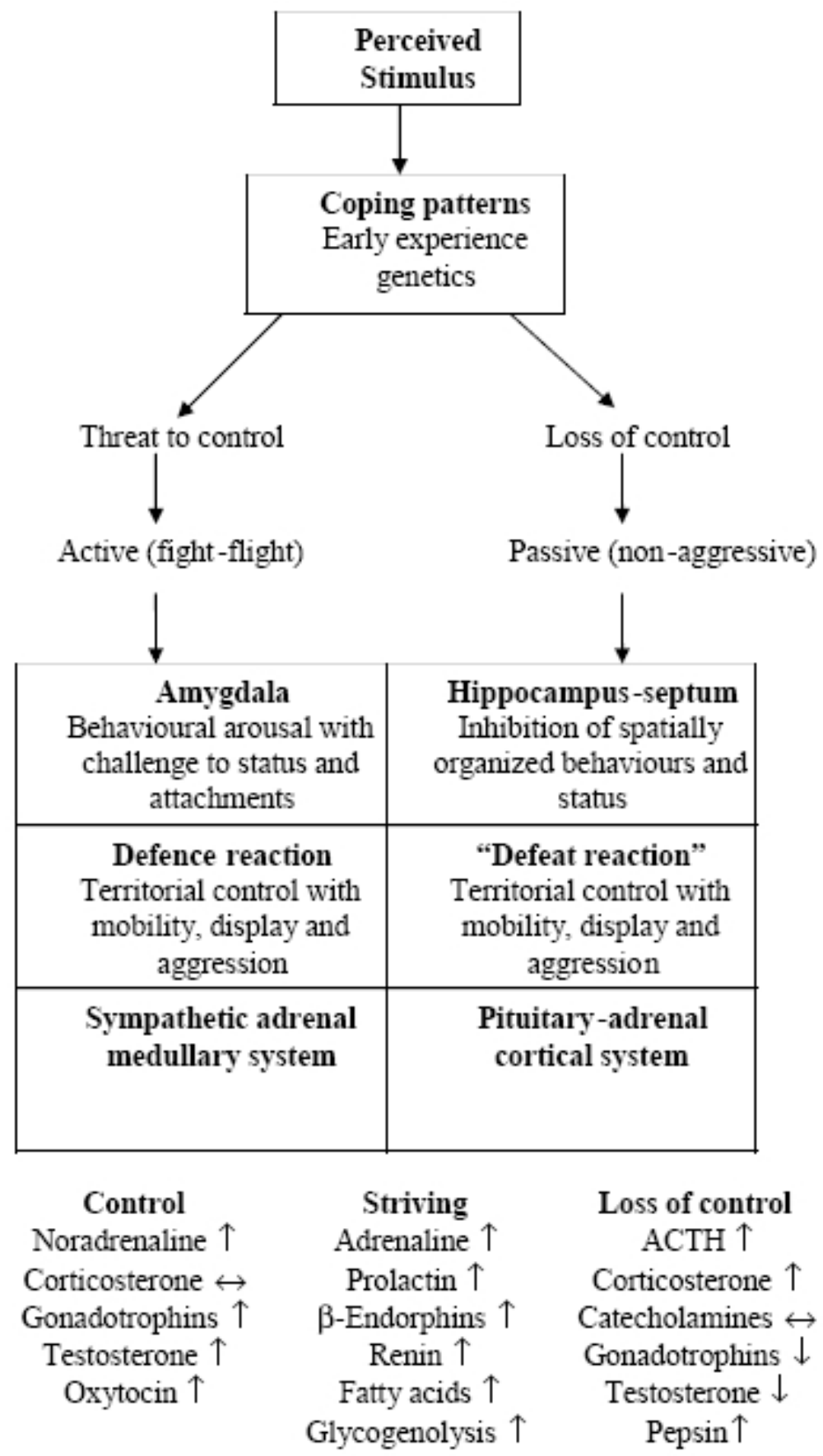

Figure 4. Psychophysiological stress model according to Henry (1992). Adapted from Ising \& Krupp (2004).

Another novel line of inquiry targets the neural correlates of human experience with brain imaging modalities. This technology has not been widely applied to human dimensions of natural resources issues, though there are a few examples of empirical research that suggest 
further attention is warranted. Irwin, Hall, Peters, and Plack (2011) used functional magnetic resonance imaging (fMRI) to investigate the response of the brain to natural and urban soundscapes. This study complemented brain activation data with other physiological measurements and ratings of affect to demonstrate how multiple methods can be combined to develop a more comprehensive, multi-dimensional approach to the study of natural resource issues. According to the authors, this approach represents "the first evaluation of the neural basis of the cognitive and emotional response to a wide range of soundscape stimuli recorded in naturalistic urban environments” (Irwin et al., 2011, p. 259).

Another recent study used fMRI to look at the complex interaction between visual and auditory factors in the experience of tranquility (Hunter et al., 2010). This study aimed to separate the subjective experience of natural environments from its objective sensory components, a goal that would likely be impossible without looking at subconscious, neurobiological processes. Connectivity in patterns of activation across different areas of the brain - areas that are associated with different psychological processes (i.e., visual processing, auditory processing, or emotional response) - can be analyzed to inform how these individual psychological components combine to produce the highly subjective experience of tranquility. As with physiological monitoring, brain imaging represents a new approach to the study of the benefits of natural environments that could expand the reach of existing human dimensions theories beyond the cognitive and behavioral domains. 


\section{SUMMARY}

The accumulation of research from different theoretical frameworks, methodologies, participant populations, and sites around the world clearly suggests that humans are likely to gain a wide range of benefits from the preservation of natural soundscapes, especially in protected areas. These benefits take the form of recovery from stress, renewal of depleted attentional capacities, increased positive feelings, and improved cognitive performance. There are invaluable benefits derived from the presence of wildlife species, when they are not disturbed or displaced by anthropogenic noise, and there are also benefits to the ecosystem when wildlife behavior remains within the historic range of variability. There are links between natural environments and immunization against stress; when research participants are tested in simulated natural environments, not only do they show improved recovery from stress, but there is also evidence to suggest that the effects of future stressors are attenuated (Parsons, Tassinary, Ulrich, Hebl, \& Grossman-Alexander, 1998). In other words, natural environments may have protective qualities that prevent stress responses in the first place. Studies with children suggest that those who live in areas with greater access to nearby nature experience less impact of stressful life events on their psychological well-being (Wells \& Evans, 2003). As these results and others like them demonstrate, the potential benefits of preserving natural soundscapes in protected areas justify a great deal of attention from public land managers. Whether it is the sound of a gentle breeze moving through a grove of aspen or a thundering waterfall, birds twittering at dawn or a coyote's howl at dusk, it is our responsibility to ensure that future generations experience the truly unique gift of nature’s song. 


\section{Future Research}

Future research will focus on demonstrating the positive benefits of natural soundscapes in protected areas. Psychological, physiological, and affective processes will be investigated in order to define more precisely the specific characteristics of soundscapes that produce these benefits. More work is needed to characterize the beneficial auditory and visual components of natural settings, including their interaction. “[L]andscapes and soundscapes are rarely experienced separately; however, it has not been shown that, in combination with a natural landscape, natural sound contributes any more to psychological or physical restoration than natural landscapes dominated by mechanical noise” (Gramann, 1999, p. 10). Particular attention will be paid to the emerging issue of excessive motorized transportation noise in protected areas and the associated impacts to the quality of visitor experience and derived benefits. Attitudes towards motorized sources and noise levels in protected areas will be combined with laboratory experiments exploring responses to anthropogenic noise across several systems - subjective selfreport measures and objective biological indicators. These results will be supplemented by models of sound propagation from acoustical monitoring in the field to create a comprehensive picture of the extent of the threat of motorized transportation noise and other anthropogenic intrusions on natural soundscapes, and the associated lost opportunity for beneficial experiences for affected visitors. Additional research will investigate unique opportunities for cognitive restoration and stress recovery from natural soundscapes in protected areas. These studies might extend the psychological, physiological, and affective data collection techniques to brain-based methodologies. By allowing human dimensions researchers to explore the neural correlates of cognition and behavior, as they relate to natural resource issues, functional brain imaging would 
take the field a step further towards understanding the biological basis of human interaction with the environment.

Although there is clearly more attention being paid to the importance of natural soundscapes in protected areas (take, for instance, the creation of the Natural Sounds Program by the NPS in 2000), much of the work to date has focused on characterizing the physical aspects of anthropogenic noise, such as source, intensity, duration, and spatial extent (Park, Lawson, Kaliski, Newman, \& Gibson, 2010). Less research has examined the psychological, physiological, and affective outcomes of noise on visitor experience. Furthermore, the issue is commonly approached from the perspective of the negative impacts of anthropogenic noise. Future research should aim to take a different approach: framing the issue in terms of the positive effects of natural sounds. Future studies can utilize some of the traditional tools in the human dimensions toolbox - visitor surveys about attitudes, expectations, and affect regarding soundscapes and human-caused intrusions in protected areas - while also integrating methods that are novel to human dimensions research. Physiological measurements, including heart rate and electrodermal activity, provide the ability to obtain information about biological processes operating below the level of consciousness and beyond access by traditional self-report measures. And functional brain imaging offers a more direct measure of neural processes underlying cognition and behavior, which may be less influenced by response bias and individual differences in cognitive appraisal by research participants.

The goal of this thesis is to get to the root of a natural resource issue of growing importance, while testing new methodologies that could prove invaluable to the field. By validating traditional methods of inquiry with biologically-based techniques, the work presented here will also demonstrate new research tools to the human dimensions community. The 
findings will be of practical significance to land managers hoping to mitigate the effects of increased noise intrusions in their protected areas. A long-term aim of this thesis and research program will be to raise awareness of the multi-dimensional benefits of protecting natural soundscapes, with the hope that this topic will become a priority for land management agencies and the public. The specific objective of this thesis is to build on earlier descriptive research about soundscape conditions to determine how different sources of motorized noise common in national parks impact visitor experiences aesthetically, affectively, and physiologically. It is hypothesized that motorized sources of noise will produce more negative social impacts than will natural sounds.

\section{Organization of Thesis}

This thesis summarizes three studies and is presented as three chapters suitable for journal submission. Each chapter focuses on the effects of simulated motorized noise on different dimensions of human experience in a protected area setting. In Chapter 1 , the impacts of noise on landscape assessments are compared between sound sources. These evaluations of visual scenes in the presence of different types of sound highlight anthropogenic noise impacts along a more aesthetically- and cognitively-oriented dimension. Chapter 2 explores potential effects of motorized noise on affective dimensions. A psychological scale measuring the participant's affective state is employed under different sound conditions to look for changes in self-reported feeling states. In Chapter 3, physiological monitoring technology captures the positive and negative effects of soundscape conditions that may operate on more visceral, subconscious levels that may be less accessible by self-reported survey data. Results from physiological monitoring are compared to the affective data to look for correspondence and divergence between these human dimensions. Finally, the Conclusion ties the three chapters 
together, exploring broader implications, lessons learned across methods, and next steps.

Limitations from these studies are also discussed. 


\section{CHAPTER 1. DIFFERENCES IN LANDSCAPE ASSESSMENT IN RESPONSE TO}

\section{MOTORIZED AND NATURAL SOURCES OF SOUND}

\section{Introduction}

Despite the clear need to provide opportunities for natural quiet and the established detrimental impacts of noise in protected areas, very little research has compared the effects of different common sources of noise on visitor experiences. One of the most prevalent sources of noise in many NPS units is motorized transportation noise. Both backcountry and frontcountry visitors often have several different transportation options. In addition to primitive forms of travel, like backpacking, stock use, or cross-country skiing, many parks offer trails for snowmobiling and air tours by propeller planes. National parks are also popular destinations for motorcycle groups, who take advantage of the many amenities surrounding national parks and their gateway communities.

Previous scientific research regarding motorcycle use and behavior typically concerns safety (helmet use or conspicuity, for example) but rarely human dimensions. Whereas several studies have investigated the impact of aircraft (Mace, Bell, \& Loomis, 1999; Tarrant, Haas, \& Manfredo, 1995) and snowmobiles (Davenport \& Borrie, 2005) on visitor experiences and resource conditions, little attention has been paid to motorcycles. This is somewhat surprising, given the ubiquity of motorcycles in national parks, especially in the most heavily visited areas. A recent NPS report found that visitors to the Blue Ridge Parkway were exposed to noise from an average of 25 different motorcycles over a given 20 -minute time period at a popular scenic overlook in the park (NPS, 2011). Compounding the problem, a large percentage of motorcyclists alter their exhaust systems and mufflers, whether for aesthetic reasons or perceived safety advantages ("loud pipes save lives”). Regardless of the reasoning behind the 
modifications, the result is substantially louder motorcycles (often exceeding EPA and state standards for vehicle noise). Motorcyclists also tend to ride in larger groups for social and safety reasons, which can augment the intensity and spatial penetration of their sound impacts over the landscape. Some research suggests that engine noise, in general, is evaluated as particularly annoying due to the fact that it is irregular and unpredictable. In addition, rhythmic sounds (as from motorcycle engines) are rated more negatively than continuous sounds (Kryter, 1985).

There is clearly a need for more research targeted to the psychological, social, and physiological impacts of motorized transportation noise in protected areas. This could include attitudinal ratings by park visitors about the acceptability of motorized transportation and the noise it produces in parks and other natural settings, monitoring of the extent of motorized noise and simulations of its acoustic effects, analysis of the impacts of the noise on wildlife behavior, and laboratory studies exploring psychological parameters and physiological responses to motorized transportation noise in natural settings. Such research would allow protected area managers to undertake more informed cost-benefit analyses for potentially implementing regulations to limit these sources of noise in order to protect natural soundscapes.

Managers from different NPS units have identified the noise produced by propeller planes, snowmobiles, and motorcycles as significantly impacting the social and biological resources of their parks. However, there may be important distinctions between these sources in how they impact visitors. Whether it is the physical characteristics of the noise, attitudes about the sources, themselves, or expectations for a particular park, it would not be surprising to find that visitors respond differently to noise from propeller planes, snowmobiles, and motorcycles in protected areas. Such a finding would suggest that "motorized noise" cannot be treated as a single, homogenous category for soundscape research. 


\section{Methods}

This study was conducted in a psychology laboratory at Colorado State University. The overall sample size was $N=77$. The data from 2 participants were excluded due to technical difficulties with the headphones and electronic surveys. Participants were undergraduate and graduate students enrolled at Colorado State University who volunteered in exchange for course credit. All responses were recorded on iPad $2^{\text {nd }}$ Generation computers (Apple Inc., Cupertino, CA) programmed with iSURVEY software (Contact Software Limited, Wellington, New Zealand). Landscape assessments were based on the scales and procedures described in Mace et al. (1999) and Benfield, Bell, Troup, and Soderstrom (2010). Physiological data were obtained continuously for all participants during the baseline surveys and landscape assessments. Each session lasted about one hour. Figure 5 displays the experimental design used in this study.

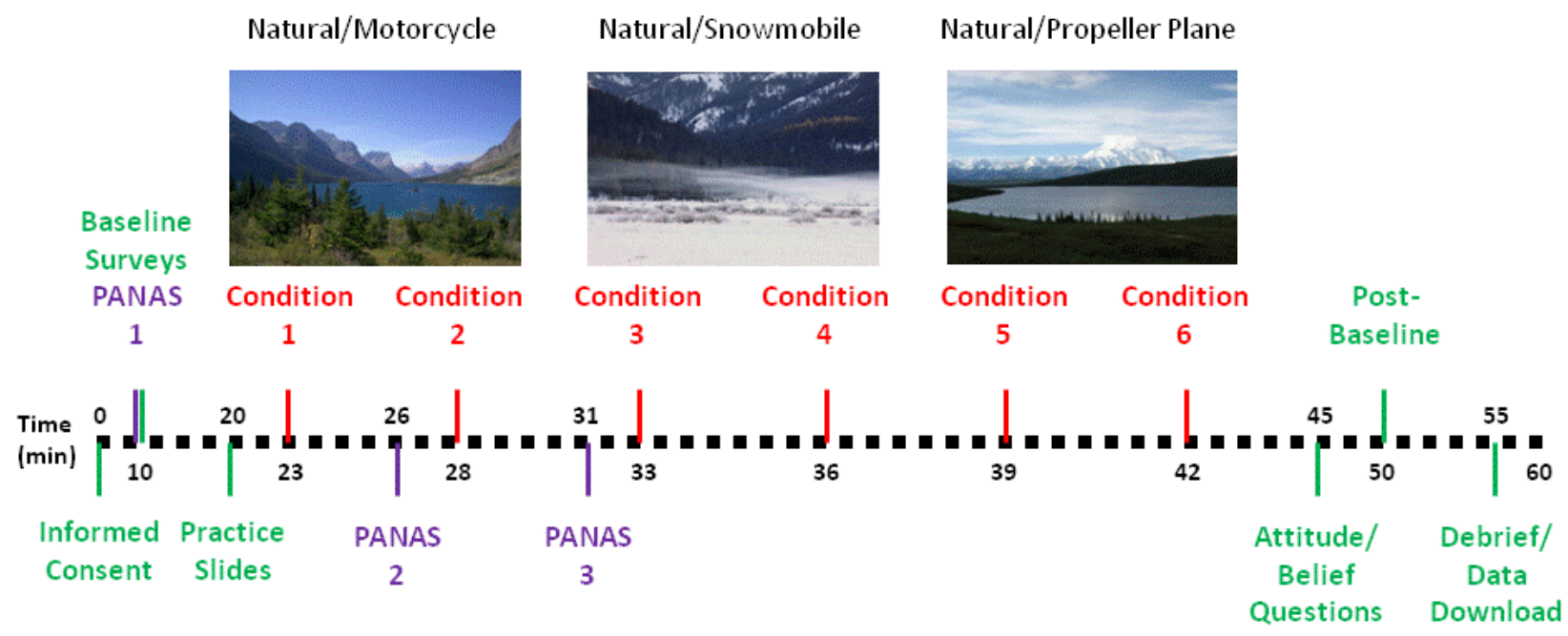

Figure 5. Overview of study design and timeline of experimental procedures.

All participants completed landscape assessments for 6 different conditions. There were 3 conditions that featured only natural sounds (i.e., birds, wind, and water sounds) -1 each recorded from Denali, Glacier, and Yellowstone National Parks. There were 3 conditions that included the natural sounds plus a superimposed motorized sound - either propeller plane, 
motorcycle, or snowmobile sounds. Each participant experienced all 6 conditions, in 1 of 6 possible pseudo-randomized orders. Different orders of conditions were used to test for the possibility of order effects. Half the participants received the natural conditions before the corresponding motorized condition; the other half received the motorized conditions first.

Six sound clips were prepared with assistance from the NPS’s Natural Sounds and Night Skies Division. All clips were extracted from actual acoustic recordings from the specific parks (in the appropriate season) represented in the laboratory simulations. Raw data files were trimmed to 45 seconds, selecting for the best window from the raw data, based on sound quality and included sound events. Seven-second fade-in and fade-out effects were added to the clips to simulate movement of the sound sources. Data files were normalized so that all natural clips had the same standardized sound energy levels, and all motorized clips had equivalent sound energy levels. The clips were then embedded into a PowerPoint presentation and tested using a Larson Davis 824 sound level meter calibrated to $94 \mathrm{~dB}$ at $1000 \mathrm{~Hz}$, paired with a GRAS artificial ear headphone system (1/2 inch microphone type 40AG) and Quiet Comfort 15 Bose headphones. Normalized sound files were calibrated so that the headphones would deliver $\sim 45 \mathrm{~dB}(\mathrm{~A})$ natural clips and $\sim 60 \mathrm{~dB}(\mathrm{~A})$ motorized clips.

Landscape photographs were obtained from park staff. Four final scenes were selected from each of the three national parks. Scenes were selected to represent typical views from scenic overlooks, without evidence of obvious anthropogenic influence. Winter scenes were selected for Yellowstone to match the snowmobile sounds. Summer scenes were selected for Denali and Glacier to pair with propeller plane and motorcycle sounds, respectively. The motorized sound sources were not visible in the scenes. Participants were instructed to imagine taking a hike in each landscape and to "try to place yourself into the scene.” Participants viewed 
each scene for 45 seconds. After 25 seconds, a message automatically appeared on each slide informing participants to complete the landscape assessments on the iPad. Two practice scenes were included prior to the actual experiment. Following the practice scenes, very few participants had difficulty completing the ratings in the allotted 20 seconds. Conditions were blocked so that participants viewed 4 slides for each condition. The corresponding sound clip was repeated with each slide so that 4 sets of landscape assessments (8 dimensions each) were obtained for each condition. This blocked design was employed so that a 3-minute total exposure to each sound source could be acquired in order to maximize the potential physiological response, while also maintaining the participants' interest.

Landscape scenes were rated according to the following dimensions: naturalness, freedom, preference, annoyance, solitude, scenic beauty, tranquility, and acceptability. Participants reported their ratings of the dimensions on a 10-point visual analog scale ranging from "Very low" (coded 1) to "Very high" (coded 10). Intermediate labels were not included on the scale. The annoyance dimension was reverse-coded prior to analysis. Repeated measures analysis of variance (ANOVA) tests and paired-samples $t$-tests were conducted on the landscape assessments to investigate whether there were significant differences between sound sources across participants.

\section{Results}

Ratings from the 4 slides in each block were averaged to obtain a mean score for each dimension in each condition. The mean scores were then combined for the 8 dimensions to get an overall rating for each condition. Tables 1 and 2 show the reliability analyses for the composite scores in the natural sounds conditions (Table 1) and the motorized sounds conditions (Table 2). The resulting Cronbach's $\alpha$ values for each condition were sufficient to justify 
combining the individual dimensions into a single rating (Cronbach's $\alpha$ for Denali natural condition $=.87$; Cronbach's $\alpha$ for Glacier natural condition $=.89$; Cronbach's $\alpha$ for Yellowstone natural condition $=.90$; Cronbach's $\alpha$ for motorcycle condition $=.85$; Cronbach's $\alpha$ for propeller plane condition $=.89$; Cronbach's $\alpha$ for snowmobile condition $=.86$ ). For several of the composite variables, the value for Cronbach's $\alpha$ could be slightly improved by removing a single item from the scale. However, the pattern was not consistent across variables; in order to maintain consistency, all items were retained in the scales. 
Table 1. Reliability analysis for landscape assessment composite natural variables

\begin{tabular}{|c|c|c|c|}
\hline Variable & $\begin{array}{l}\text { Item Total } \\
\text { Correlation }\end{array}$ & $\begin{array}{l}\text { Alpha if Item } \\
\text { Deleted }\end{array}$ & $\begin{array}{l}\text { Cronbach } \\
\text { Alpha }\end{array}$ \\
\hline Natural Denali Condition & & & .87 \\
\hline Acceptability & .76 & .84 & \\
\hline Freedom & .72 & .84 & \\
\hline Naturalness & .78 & .85 & \\
\hline Preference & .71 & .84 & \\
\hline Scenic beauty & .62 & .86 & \\
\hline Solitude & .62 & .85 & \\
\hline Tranquility & .54 & .87 & \\
\hline Annoyance $^{1}$ & .50 & .86 & \\
\hline Natural Glacier Condition & & & .89 \\
\hline Acceptability & .80 & .86 & \\
\hline Freedom & .83 & .86 & \\
\hline Naturalness & .79 & .87 & \\
\hline Preference & .75 & .87 & \\
\hline Scenic beauty & .56 & .89 & \\
\hline Solitude & .46 & .92 & \\
\hline Tranquility & .79 & .86 & \\
\hline Annoyance $^{1}$ & .65 & .88 & \\
\hline Natural Yellowstone Condition & & & .90 \\
\hline Acceptability & .78 & .87 & \\
\hline Freedom & .80 & .88 & \\
\hline Naturalness & .72 & .89 & \\
\hline Preference & .70 & .89 & \\
\hline Scenic beauty & .68 & .88 & \\
\hline Solitude & .51 & .90 & \\
\hline Tranquility & .76 & .88 & \\
\hline Annoyance $^{1}$ & .65 & .89 & \\
\hline
\end{tabular}

\footnotetext{
${ }^{1}$ Annoyance variable reverse coded
} 
Table 2. Reliability analysis for landscape assessment composite motorized variables

\begin{tabular}{|c|c|c|c|}
\hline Variable & $\begin{array}{l}\text { Item Total } \\
\text { Correlation }\end{array}$ & $\begin{array}{c}\text { Alpha if Item } \\
\text { Deleted }\end{array}$ & $\begin{array}{c}\text { Cronbach } \\
\text { Alpha }\end{array}$ \\
\hline Motorcycle Condition & & & .85 \\
\hline Acceptability & .62 & .83 & \\
\hline Freedom & .75 & .81 & \\
\hline Naturalness & .68 & .82 & \\
\hline Preference & .69 & .82 & \\
\hline Scenic beauty & .42 & .85 & \\
\hline Solitude & .68 & .82 & \\
\hline Tranquility & .75 & .81 & \\
\hline Annoyance $^{1}$ & .25 & .88 & \\
\hline Propeller Condition & & & .89 \\
\hline Acceptability & .76 & .87 & \\
\hline Freedom & .74 & .87 & \\
\hline Naturalness & .65 & .88 & \\
\hline Preference & .75 & .87 & \\
\hline Scenic beauty & .50 & .89 & \\
\hline Solitude & .75 & .87 & \\
\hline Tranquility & .81 & .86 & \\
\hline Annoyance $^{1}$ & .46 & .90 & \\
\hline Snowmobile Condition & & & .86 \\
\hline Acceptability & .68 & .83 & \\
\hline Freedom & .80 & .81 & \\
\hline Naturalness & .64 & .83 & \\
\hline Preference & .62 & .84 & \\
\hline Scenic beauty & .45 & .85 & \\
\hline Solitude & .63 & .84 & \\
\hline Tranquility & .77 & .82 & \\
\hline Annoyance $^{1}$ & .31 & .88 & \\
\hline
\end{tabular}

\footnotetext{
${ }^{1}$ Annoyance variable reverse coded
} 
The descriptive statistics for the composite variables for each condition are displayed in Table 3. The mean values across participants for the natural sound conditions were "very high" (Denali: $M=9.24, S D=0.64$; Glacier: $M=9.27, S D=0.65$; Yellowstone: $M=9.05, S D=0.79$ ). The mean values for the motorized sound conditions, however, were more neutral with higher variance (propeller plane: $M=6.21, S D=1.51$; motorcycle: $M=5.73, S D=1.35$; snowmobile: $M=5.89, S D=1.44)$. Difference scores were computed by subtracting the motorized source from the corresponding natural condition (Table 4, Denali natural - propeller plane: $M=3.03$, $S D=1.47,33 \%$ reduction; Glacier natural - motorcycle: $M=3.55, S D=1.31$, 38\% reduction; Yellowstone natural - snowmobile: $M=3.16, S D=1.33,35 \%$ reduction). These scores indicate how much participants' ratings changed in the motorized conditions relative to the natural conditions and represent an internal baseline that controls for differences among and between parks. Thus, a higher score signifies a larger change from the natural sound baseline condition. This is important given that each motorized source was tested in only a single park (where it has the highest management concern).

Table 3. Descriptive statistics for landscape assessment composite variables

\begin{tabular}{ccc}
\hline Variable $^{1}$ & Mean $^{2}$ & SD \\
\hline Natural (Denali) & 9.24 & 0.64 \\
Natural (Glacier) & 9.27 & 0.65 \\
Natural (Yellowstone) & 9.05 & 0.79 \\
Propeller Plane & 6.21 & 1.51 \\
Motorcycle & 5.73 & 1.35 \\
Snowmobile & 5.89 & 1.44 \\
\hline
\end{tabular}

${ }^{1}$ Computed by averaging 8 dimensions

${ }^{2}$ Coded 1 = "very low" to 10 = "very high" 
Table 4. Descriptive statistics for landscape assessment difference scores

\begin{tabular}{cccc}
\hline Variable & Mean & SD & \% Diff \\
\hline Natural (Denali) - Propeller Plane & 3.03 & 1.47 & 33 \\
Natural (Glacier) - Motorcycle & 3.55 & 1.31 & 38 \\
Natural (Yellowstone) - Snowmobile & 3.16 & 1.33 & 35 \\
\hline
\end{tabular}

In order to test for global differences between natural and motorized conditions, the three natural conditions were combined $(M=9.19, S D=0.60)$ and compared to the three motorized conditions $(M=5.94, S D=1.31)$ by a paired-samples $t$-test. The results indicate that there is indeed a significant difference in landscape assessments between natural and motorized conditions overall, $t(74)=23.36, p<.001$ (Table 5). This finding supports the expectation that landscape assessments would be lower (more negative) in motorized noise conditions than in natural sounds conditions, across aesthetic dimensions.

Table 5. Paired samples $t$-test between landscape assessment natural and motorized conditions

\begin{tabular}{cccccc}
\hline Variable $^{1}$ & Mean $^{2}$ & $S D$ & $\mathrm{df}$ & $t$ & $p$ \\
\hline NATURAL & 9.19 & 0.60 & \multirow{2}{*}{74} & 23.26 & $<.001$ \\
MOTORIZED & 5.94 & 1.31 & & & \\
\hline
\end{tabular}

${ }^{1}$ Computed by averaging 3 composite scores

${ }^{2}$ Coded 1 = "very low" to 10 = "very high"

To determine whether landscape assessments differed between the three motorized noise sources (i.e., the impact of motorcycle, snowmobile, and propeller plane noise had differential effects on visitor experiences), repeated measures ANOVA was utilized to test for withinsubjects differences between sound conditions. Repeated measures ANOVA, which accounts for individual variability in participants' ratings, was conducted for the composite variables, as well as for the 8 individual dimensions (Table 6). Mauchly’s Test of Sphericity was used to test the assumption that the variance of the difference of all variables was a constant. Where Mauchly's Test indicated that the assumption was violated (for the freedom and naturalness dimensions), the Greenhouse-Geisser correction was used to adjust the $F$-value and degrees of freedom 
obtained from the repeated measures ANOVA. The difference scores for the 3 motorized sources of noise differed in 6 of 8 dimensions, as well as for the combined variables (overall: $F(2)=8.50, p<.001$, partial $\eta^{2}=.10$; acceptability: $F(2)=5.97, p=.003$, partial $\eta^{2}=.08$; freedom: $F(1.8)=4.24, p=.019$, partial $\eta^{2}=.05$; naturalness: $F(1.8)=6.09, p=.004$, partial $\eta^{2}$ $=.08$; preference: $F(2)=8.38, p<.001$, partial $\eta^{2}=.10$; solitude: $F(2)=7.81, p=.001$, partial $\eta^{2}$ $=.10$; tranquility: $F(2)=3.28, p=.040$, partial $\left.\eta^{2}=.04\right)$. The difference scores were not significantly different for the annoyance and scenic beauty dimensions (annoyance: $F(2)=1.65$, $p=.196$, partial $\eta^{2}=.02$; scenic beauty: $F(2)=0.86, p=.426$, partial $\eta^{2}=.01$ ).

Table 6. Tests of within-subjects effects from landscape assessment repeated measures ANOVA

\begin{tabular}{ccccc}
\hline Variable & df & $F$ & $p$ & partial $\eta^{2}$ \\
\hline OVERALL & 2 & 8.50 & $<.001^{*}$ & .10 \\
Acceptability & 2 & 5.97 & $.003^{*}$ & .08 \\
Annoyance & 2 & 1.65 & .196 & .02 \\
Freedom & $1.8^{1}$ & 4.24 & $.019^{*}$ & .05 \\
Naturalness & $1.8^{1}$ & 6.09 & $.004^{*}$ & .08 \\
Preference & 2 & 8.38 & $<.001^{*}$ & .10 \\
Scenic Beauty & 2 & 0.86 & .426 & .01 \\
Solitude & 2 & 7.81 & $.001^{*}$ & .10 \\
Tranquility & 2 & 3.28 & $.040^{*}$ & .04 \\
\hline
\end{tabular}

${ }^{1}$ Sphericity cannot be assumed; Greenhouse-Geisser correction used to adjust degrees of freedom

* Significant at $p<.05$

For the 6 individual dimensions and the combined variable with a significant $F$-value from the repeated measures ANOVA, pair-wise comparisons were conducted to determine between which conditions the significant differences lie. Paired-samples t-tests were run for each comparison (3 comparisons per variable), and the Bonferroni correction was used to adjust the alpha level for multiple comparisons (Table 7). For 5 of the 8 individual aesthetic dimensions (acceptability, freedom, naturalness, preference, and solitude) and the combined 
variable, motorcycle noise had a significantly stronger negative impact on landscape assessments relative to the natural sounds condition than propeller plane or snowmobile noise. For the annoyance, scenic beauty, and tranquility dimensions, there were no significant differences in the ratings between motorized sound sources at the Bonferroni-corrected alpha level. There were no significant differences in the decline in ratings from the natural baseline between the propeller plane and snowmobile noise conditions for any of the aesthetic dimensions.

Table 7. Means (standard deviations), percent reductions, and pair-wise comparisons between landscape assessment difference scores

\begin{tabular}{ccccccc}
\hline Variable & Motorcycle & \% Diff & Propeller & \% Diff & Snowmobile & \% Diff \\
\hline OVERALL & $3.55^{\mathrm{a}}(1.31)$ & 38 & $3.03^{\mathrm{b}}(1.47)$ & 33 & $3.16^{\mathrm{b}}(1.33)$ & 35 \\
Acceptability & $4.24^{\mathrm{a}}(2.04)$ & 46 & $3.65^{\mathrm{b}}(2.19)$ & 40 & $3.74^{\mathrm{b}}(2.25)$ & 42 \\
Annoyance & $5.58(2.43)$ & 58 & $5.15(2.80)$ & 54 & $5.25(2.71)$ & 56 \\
Freedom & $2.98^{\mathrm{a}}(2.11)$ & 32 & $2.44^{\mathrm{b}}(1.85)$ & 26 & $2.66^{\mathrm{b}}(2.08)$ & 29 \\
Naturalness & $2.56^{\mathrm{a}}(1.80)$ & 27 & $2.00^{\mathrm{b}}(1.72)$ & 21 & $2.13^{\mathrm{ab}}(1.60)$ & 23 \\
Preference & $3.27^{\mathrm{a}}(1.92)$ & 36 & $2.54^{\mathrm{b}}(2.00)$ & 29 & $2.62^{\mathrm{b}}(1.98)$ & 30 \\
Scenic Beauty & $0.80(1.05)$ & 8 & $0.72(0.95)$ & 8 & $0.88(1.02)$ & 10 \\
Solitude & $4.33^{\mathrm{a}}(2.20)$ & 43 & $3.58^{\mathrm{b}}(2.22)$ & 38 & $3.77^{\mathrm{b}}(2.18)$ & 41 \\
Tranquility & $4.61(2.04)$ & 50 & $4.18(2.38)$ & 43 & $4.24(2.03)$ & 48 \\
\hline
\end{tabular}

Note. Means with different letter superscripts differ significantly at $p<.017$ (Bonferronicorrected for 3 comparisons per variable)

A final analysis investigated whether there were order effects for any of the 6 composite variables, depending on which of the 6 possible orders of slide presentations and sound conditions the participants received. Six separate one-way ANOVAs were performed to look for significant differences in composite scores based on order (Table 8). Of the 6 composite variables, 5 showed no significant differences in order (Glacier natural: $F(5,69)=0.77, p=.574$; Yellowstone natural: $F(5,69)=2.16, p=.069$; propeller plane: $F(5,69)=1.08, p=.381$; motorcycle: $F(5,69)=0.42, p=.832$; snowmobile: $F(5,69)=0.67, p=.648)$. Only the Denali natural sound condition produced a significant difference between orders, $F(5,69)=2.60, p=$ 
.033. However, Bonferroni post-hoc tests revealed no significant differences in the pair-wise comparisons between the various orders of slide presentations and sound conditions. Taken together, these results suggest that order was not an important factor in participants' ratings of the landscapes. This finding further supports the creation of composite variables for the sound conditions, combined across different slide and sound orders.

Table 8. Comparison of landscape assessment sound condition order effects using one-way ANOVA

\begin{tabular}{cccc}
\hline Variable & $\mathrm{df}$ & $F$ & $p$ \\
\hline Natural (Denali) & 5,69 & 2.60 & $.033^{*}$ \\
Natural (Glacier) & 5,69 & 0.77 & .574 \\
Natural (Yellowstone) & 5,69 & 2.16 & .069 \\
Propeller Plane & 5,69 & 1.08 & .381 \\
Motorcycle & 5,69 & 0.42 & .832 \\
Snowmobile & 5,69 & 0.67 & .648 \\
\hline
\end{tabular}

* One-way ANOVA significant at $p<.05$. Bonferroni post-hoc tests revealed no significant differences $(p>.05)$ in pair-wise comparisons between orders.

\section{Discussion}

This laboratory simulation demonstrated the detrimental cognitive effects of motorized noise on the experiences of potential park visitors. Landscape assessments along 8 aesthetic dimensions were evaluated very highly in natural sounds conditions (i.e., birds, wind, and water) across 3 national park settings. When motorized vehicle noise was superimposed on the natural sounds, however, landscape ratings were negatively impacted. Moreover, the extent of the decline in ratings differed between the motorized sound sources on most of the dimensions. In all cases where there was a significant decline, motorcycle noise was most detrimental to participants’ reported experiences. Noise from propeller planes and snowmobiles did not produce significant differences in the decline of ratings. Two of the dimensions that did not show significant differences between sound sources were the most extreme dimensions. 
Participants evaluated the motorized noise sources as most severely impacting the landscape assessments for the annoyance dimension. All motorized sources increased participants' ratings of annoyance more than the decline in any other dimension. By contrast, motorized noise had little impact on participants' assessments of scenic beauty for the landscapes. In all 6 sound conditions (including the motorized noise conditions) scenic beauty was rated very highly, suggesting that participants were separating the visual and auditory components of the total experience.

\section{Management Implications}

This study validates the wisdom of preserving highly natural park soundscapes, just like other biophysical and social resources, as NPS policy requires. Managers should be aware of the anthropogenic noises common in their parks and how those noises are evaluated by their visitors. Some parks may have issues with excessive motorcycle noise; others may have conflicts between user groups due to backcountry use of snowmobiles in winter; still others may receive visitor complaints due to the high number of scenic air tours that disturb wilderness values. While the current findings suggest that motorcycle noise should be a top priority for management attention, in all cases, managers should take steps to protect the experiences and opportunities for which visitors come to their parks - whether by education or by regulation. Just like visitor crowding, vegetation impacts, or unhealthy air quality, park soundscapes characterized by high levels of anthropogenic noise can impair visitor satisfaction and undermine potential benefits. The findings from the present study underscore for park managers the importance of protecting natural soundscapes, especially from excessive motorized noise. Providing opportunities to experience natural sounds is a central factor contributing to visitors' evaluations of acceptable resource and experiential conditions. Participants in the current laboratory simulation clearly 
perceived and evaluated the landscapes more favorably on a variety of aesthetic dimensions when they experienced natural, rather than motorized, sounds. 
CHAPTER 2. CHANGES IN SELF-REPORTED AFFECT IN RESPONSE TO MOTORIZED AND NATURAL SOURCES OF SOUND

\section{Introduction}

There has been a notable lack of research in the human dimensions of natural resources field investigating the impacts of emotions and affective states. There has been even less prior exploration of interactions between sound, affect, and physiological arousal (Bradley \& Lang, 2000). Thus, important progress can be made in the field by linking affective aspects of the human response to the environment (including soundscapes) with cognitive and perceptual dimensions that are more commonly studied. Despite a lack of consensus about the definition of emotion and affect, it is important to attempt to clarify the terminology. According to Rosenberg (1998), “affect” is the broadest term, making reference to feeling states, generally. "Emotion” and "mood” are more specific concepts falling under affect. Manfredo (2008) distinguishes emotion from mood as follows: "Emotions are different from moods because emotions are about a specific event, have short duration, and occupy conscious thought” (p. 51). Based on this terminology, in the present study, affect is being measured when the participants are asked to report their general feeling states. However, once the different visual and auditory stimuli in the experiment are introduced, emotional reactions to specific situations are also elicited, which may alter affective states. Participants’ autonomic reactivity and physiological responses to the stimuli may reflect underlying affective states associated with their experiences, but it is only possible to measure levels of arousal directly. As Barrett et al. (2004) argue, making a causal link between physiological changes and specific emotions is a tenuous proposition. Nevertheless, it is widely believed that there is a strong connection between the concepts. 
Emotion has an important orienting effect in an individual's environment, preparing the individual to make an appropriate behavioral response. An expression of emotion also demonstrates that whatever particular event evoked it is important and significant to the individual - regardless of the valence (positive or negative) of the emotion-eliciting event. Thus, it is theoretically possible to make inferences about value orientations and norms based on emotional responses (Manfredo, 2008). While there is research that links the expression of negative emotions to poor health outcomes (Mayne, 2001), the corresponding connection between positive emotions and beneficial health outcomes is more speculative. As Manfredo (2008) says, "The positive effects on human experience via emotions is an under-explored topic" (p. 68). As a result, one broader goal of this thesis and research program is to take an initial step towards a greater understanding of the potential benefits to park visitors from positive affective states that are induced, at least in part, by natural sounds and natural quiet in protected areas.

\section{Methods}

The 20-item Positive and Negative Affect Scale (PANAS; Watson, Clark, \& Tellegen, 1988) was completed by participants at 3 distinct times during the study - at baseline, following the first sound condition (natural or motorized), and following the second sound condition (natural or motorized). Thus, each participant completed the PANAS following one of the natural conditions and one of the motorized conditions, but the specific conditions and sequence varied between participants, depending on the slide and sound condition order presented. Participants used a 5-point scale to indicate to what extent a list of words that describe different feelings represent how they are feeling at that exact moment (i.e., "excited”, "alert”, "irritable”). The scale ranged from "Very slightly or not at all” (coded 1) to "Extremely" (coded 5). 
Responses from 10 of the items are combined to give a positive affect score, and responses from the other 10 items are combined to provide a negative affect score.

Sensitivity to noise was measured at baseline using the 5-item abbreviated version of the Weinstein Noise Sensitivity Scale (NSS; Weinstein, 1978). An additional item from the original scale was included due to its potential relevance to the present study ("Motorcycles ought to be required to have bigger mufflers"). Participants used a 6-point scale to indicate to what extent they disagreed or agreed with a list of statements. The scale ranged from "Disagree strongly" (coded 1) to "Agree strongly" (coded 6). The 5-item short form of the NSS (NSS-SF) has been validated previously (Benfield et al., 2012), and it produces consistent psychometric results as the original 21-item NSS.

The New Environmental Paradigm (NEP) is a scale that was created in 1978 to measure shifting environmental value orientations in society (Dunlap \& Van Liere, 1978). The original 12-item scale has since been revised and expanded to 15 items that are more relevant to today's environmental issues (Dunlap, Van Liere, Mertig, \& Jones (2000). The revised version, which was used in this study, contains questions addressing the following dimensions: balance of nature, anti-exemptionalism, limits to growth, anti-anthropocentrism, and eco-crisis. During the baseline period, participants used a 5-point scale to indicate to what extent they disagreed or agreed with a list of statements. The scale ranged from "Strongly disagree" (coded 1) to "Strongly agree" (coded 5). A single composite score from all 15 items was created for the purposes of this study. For the original scale, NEP correlated with age, education level, and political orientation, suggesting good construct validity. The authors also reported good predictive validity, citing strong correlations between the NEP and other pro-environmental measures (Dunlap \& Van Liere, 1978). Despite having its critics, the NEP (and its revised 
versions) has been widely used in research as a measure of environmental concern for the past three decades (Dunlap, 2008). Here composite NEP scores are interpreted as indicators of environmental value orientations.

Demographic variables, including sex, age, college major, and zip code were obtained at baseline. Participants also provided information about the population of their home town or city, their political ideology, and previous experience in protected areas (i.e., time since last visit, number of hikes). Finally, participants indicated which of the national parks represented in the landscape assessments (Denali, Yellowstone, or Glacier) they had visited previously.

Thirteen attitude and belief statements were evaluated by study participants following the landscape assessments. These statements related to the use of motorized vehicles for recreation, particularly in the context of national parks. Participants used a 7-point scale to indicate to what extent they disagreed or agreed with each statement. The scale ranged from "Strongly disagree" (coded 1) to "Strongly agree" (coded 7). One set of statements related to feelings of excitement when hearing motorcycles, propeller planes, and snowmobiles pass. Another set of statements concerned the appropriateness of park managers regulating motorized activities and noise. Participants indicated their willingness to travel by motorized recreational vehicles through parks if the noise generated bothered other visitors. They also evaluated statements pertaining to possible prohibition of motorized recreational vehicles in national parks. The remaining statements elicited opinions about possible tradeoffs between vehicle noise, economic benefits, and opportunities to view wildlife.

\section{Results}

As described above, positive and negative affect were measured at 3 time points during the experiment. PANAS1 was obtained during the baseline period, PANAS2 was obtained 
following the first sound condition (natural or motorized), and PANAS3 was obtained following the second sound condition (natural or motorized). Changes in positive and negative affect were calculated by subtracting the scores for each dimension (comprised of 10 items) from the values from the preceding administration and converting to a percent change. One-way analysis of variance (ANOVA) was used to determine if there were differences in the change in positive and negative affect between conditions. Where the ANOVA produced significant findings, post-hoc tests (Bonferroni and Tamhane T2) were performed to identify the specific conditions where there were significant differences in change in affect. The changes in positive and negative affect from PANAS1 to PANAS2 are displayed in Figure 6 and Table 9. Positive affect showed the largest decrease following the motorcycle condition (-21\%), followed by propeller plane (12\%) and snowmobile (-11\%). Positive affect increased slightly after each of the natural sounds conditions $($ Yellowstone $=5 \%$, Denali $=2 \%$, Glacier $=1 \%)$. Negative affect increased most following the propeller plane (28\%) and motorcycle (17\%) conditions. Negative affect actually decreased slightly after the snowmobile condition (-3\%), as well as after each of the natural sounds conditions $($ Glacier $=-21 \%$, Yellowstone $=-14 \%$, Denali $=-4 \%)$.

Table 9. Means (standard deviations), percent reductions, and pair-wise comparisons between PANAS1 and PANAS2

\begin{tabular}{ccccc}
\hline Condition & Positive Affect $^{1}$ & \% Diff & Negative Affect $^{2}$ & \% Diff \\
\hline Natural (GLAC) & $-0.01^{\mathrm{a}}(0.51)$ & 1 & $0.36^{\mathrm{a}}(0.37)$ & -21 \\
Natural (DENA) & $-0.09^{\mathrm{a}}(0.42)$ & 2 & $0.06^{\mathrm{ab}}(0.21)$ & -4 \\
Natural (YELL) & $-0.13^{\mathrm{a}}(0.42)$ & 5 & $0.28^{\mathrm{ab}}(0.53)$ & -14 \\
Motorcycle & $0.69^{\mathrm{b}}(0.69)$ & -21 & $-0.28^{\mathrm{b}}(0.39)$ & 17 \\
Propeller plane & $0.35^{\mathrm{ab}}(0.37)$ & -12 & $-0.32^{\mathrm{ab}}(0.82)$ & 28 \\
Snowmobile & $0.33^{\mathrm{ab}}(0.54)$ & -11 & $0.04^{\mathrm{ab}}(0.23)$ & -3 \\
\hline
\end{tabular}

${ }^{1}$ Bonferroni post-hoc test used for pair-wise comparisons for positive affect

${ }^{2}$ Tamhane T2 post-hoc test used for pair-wise comparisons for negative affect Note. Different superscripts represent significant mean differences between conditions 

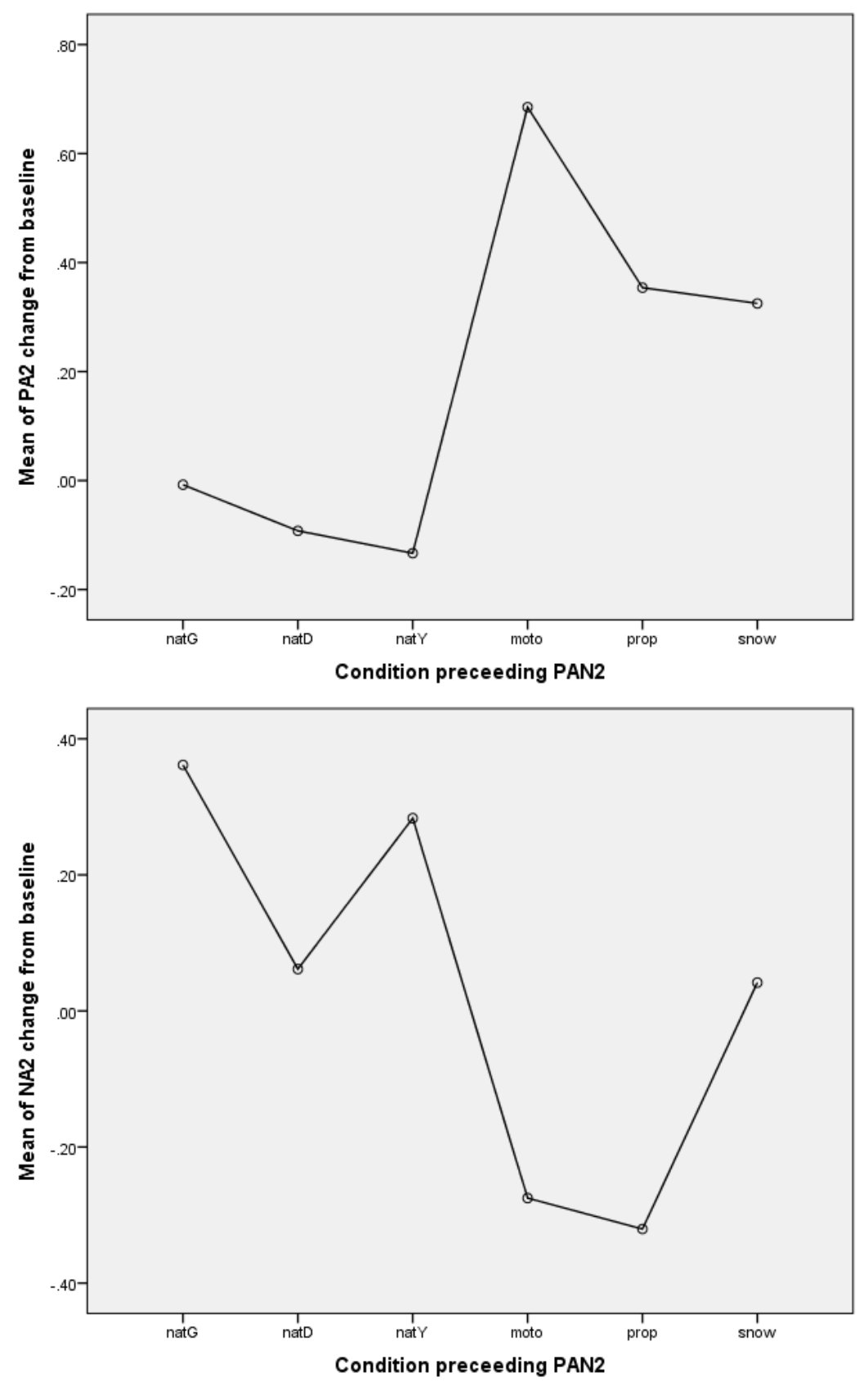

Figure 6. Change in positive (top) and negative (bottom) affect from PANAS1 to PANAS2 following each sound condition (natG = Glacier natural sounds; natD = Denali natural sounds; natY = Yellowstone natural sounds; moto = motorcycle; prop = propeller plane; snow = snowmobile).

The ANOVA for positive affect yielded significant differences between conditions, $F(5$, 69) $=5.80, p<.001, \eta^{2}=.30$. There was a significant decline in positive affect for participants who received the motorcycle noise condition first $(M=0.69, S D=0.69)$, relative to those 
participants who received any of the natural sounds conditions first (Glacier: $M=-0.01, S D=$ 0.51, $p=.006$; Denali: $M=-0.09, S D=0.42, p=.001$; Yellowstone: $M=-0.13, S D=0.42, p=$ .001). The ANOVA for negative affect yielded significant differences between conditions, $F(5$, $69)=4.39, p=.002, \eta^{2}=.24$. There was a significant increase in negative affect for participants who received the motorcycle noise condition first $(M=-0.28, S D=0.39)$, relative to those participants who received the Glacier natural sounds condition first (Glacier: $M=0.36, S D=$ $0.37, p=.006)$.

The changes in positive and negative affect from PANAS2 to PANAS3 are displayed in Figure 7 and Table 10. Positive affect showed the largest decrease after the motorcycle condition (-20\%), followed by snowmobile (-19\%) and propeller plane (-17\%). Positive affect increased after each of the natural sounds conditions (Denali $=13 \%$, Glacier $=9 \%$, Yellowstone $=8 \%)$. Negative affect increased most subsequent to the propeller plane condition (34\%), followed by the motorcycle (32\%) and snowmobile (31\%) conditions. Negative affect decreased after each of the natural sounds conditions (Glacier $=-30 \%$, Denali $=-18 \%$, Yellowstone $=$ $10 \%)$.

Table 10. Means (standard deviations), percent reductions, and pair-wise comparisons between PANAS2 and PANAS3

\begin{tabular}{ccccc}
\hline Condition & Positive Affect $^{1}$ & \% Diff & Negative Affect $^{2}$ & \% Diff \\
\hline Natural (GLAC) & $-0.18^{\mathrm{a}}(0.63)$ & 9 & $0.62^{\mathrm{a}}(0.45)$ & -30 \\
Natural (DENA) & $-0.26^{\mathrm{a}}(0.64)$ & 13 & $0.47^{\mathrm{a}}(0.79)$ & -18 \\
Natural (YELL) & $-0.18^{\mathrm{a}}(0.32)$ & 8 & $0.17^{\mathrm{a}}(0.31)$ & -10 \\
Motorcycle & $0.66^{\mathrm{b}}(0.61)$ & -20 & $-0.38^{\mathrm{b}}(0.38)$ & 32 \\
Propeller plane & $0.48^{\mathrm{b}}(0.34)$ & -17 & $-0.37^{\mathrm{b}}(0.38)$ & 34 \\
Snowmobile & $0.60^{\mathrm{b}}(0.38)$ & -19 & $-0.38^{\mathrm{b}}(0.21)$ & 31 \\
\hline
\end{tabular}

\footnotetext{
${ }^{1}$ Bonferroni post-hoc test used for pair-wise comparisons for positive affect

${ }^{2}$ Tamhane T2 post-hoc test used for pair-wise comparisons for negative affect Note. Different superscripts represent significant mean differences between conditions.
} 

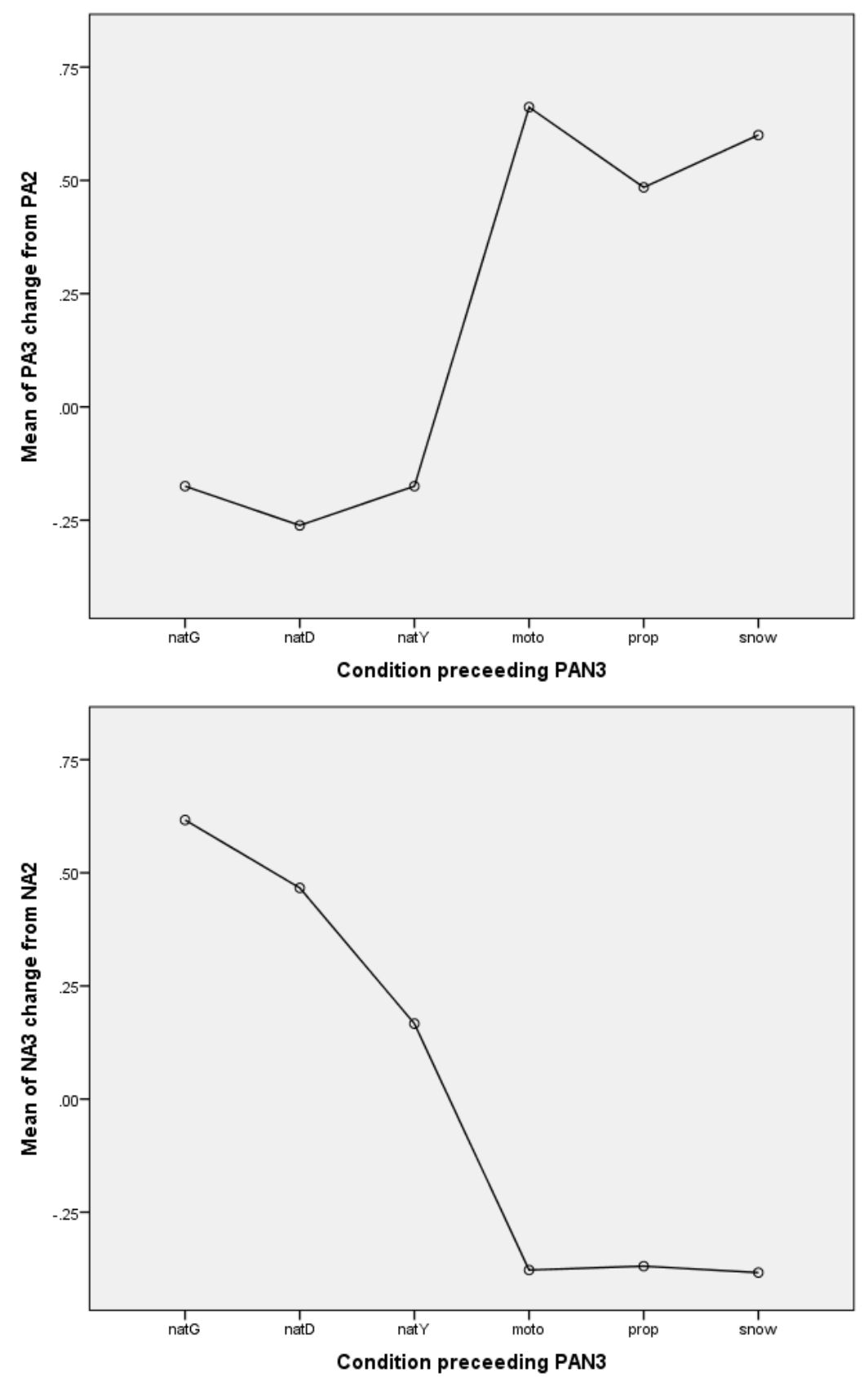

Figure 7. Change in positive (top) and negative (bottom) affect from PANAS2 to PANAS3 following each sound condition (natG = Glacier natural sounds; natD = Denali natural sounds; natY = Yellowstone natural sounds; moto = motorcycle; prop = propeller plane; snow = snowmobile).

The ANOVA for positive affect yielded significant differences between conditions, $F(5$, $69)=9.21, p<.001, \eta^{2}=.40$. There was a significant decline in positive affect for participants who received the motorized noise conditions (motorcycle: $M=0.66, S D=0.61$; propeller: $M=$ 
$0.48, S D=0.34$; snowmobile: $M=0.60, S D=0.38$ ), relative to those participants who received the natural sounds conditions (Glacier: $M=-0.18, S D=0.63$; Denali: $M=-0.26, S D=0.64$; Yellowstone: $M=-0.18, S D=0.32$ ). Positive affect following all 3 motorized noise sources was significantly lower than positive affect following any of the 3 natural sounds conditions (all Bonferroni post-hoc comparisons $p<.03$ ). The ANOVA for negative affect yielded significant differences between conditions, $F(5,69)=12.26, p<.001, \eta^{2}=.47$. There was a significant increase in negative affect for participants who received the motorized noise conditions (motorcycle: $M=-0.38, S D=0.38$; propeller: $M=-0.37, S D=0.38$; snowmobile: $M=-0.38, S D$ $=0.21$ ), relative to those participants who received the natural sounds conditions (Glacier: $M=$ 0.62, $S D=0.45$; Denali: $M=0.47, S D=0.79$; Yellowstone: $M=0.17, S D=0.31$ ). Negative affect following all 3 motorized noise sources was significantly higher than negative affect following any of the 3 natural sounds conditions (all Tamhane T2 post-hoc comparisons $p<.05$ ).

\section{Discussion}

When comparing the change in affect from the baseline period (PANAS1) to the first sound condition (PANAS2), participants who experienced motorcycle noise demonstrated significantly lower positive affect and higher negative affect than those participants who heard natural sounds. The magnitude of the change in affect was approximately $20 \%$, a substantial change given the only difference between the two types of conditions was the presence of motorcycle noise from an unseen source. When comparing changes in affect from the first sound condition (PANAS2) to the second sound condition (PANAS3), the changes became even more apparent. In this case, all 3 motorized noise sources evoked significant decreases in positive affect ( 20\%) and significant increases in negative affect ( 30\%) relative to the natural sounds conditions. It is interesting to note that changes in affect appeared to intensify between PANAS2 
and PANAS3 (compared to changes between PANAS1 and PANAS2), after participants had experienced both types of sound conditions - natural and motorized. This perhaps suggests that participants' appraisals of their affective states became increasingly “crystallized” after proceeding through the experiment and being exposed to more sound conditions (especially when considering the smaller standard deviations in the motorized conditions preceding PANAS3). Although it was not investigated directly, there was also an indication that the natural sounds provided a restorative effect for participants, i.e., an increase in positive affect and a decrease in negative affect relative to their preceding self-reported affective state. This trend deserves additional attention in future studies.

\section{Management Implications}

It was outlined above how positive affective states can impact the experiences, satisfaction, and benefits accrued by visitors to protected areas. The results from the selfreported affective measures obtained in this study underscore the importance of providing opportunities to experience natural quiet and the sounds of nature. The mere presence of motorized noise, without a visible source of the noise, was enough to increase feelings of negative affect in participants by greater than $30 \%$. Similarly, natural sounds were shown to improve participants' affective states, even compared to what they reported feeling during the baseline period. These results provide justification for a stronger commitment from protected area managers to assure that their units provide respite from motorized noise for the affective health and well-being of visitors. 
CHAPTER 3. PHYSIOLOGICAL RESPONSE TO MOTORIZED AND NATURAL SOURCES OF SOUND

\section{Introduction}

This thesis aims to illustrate the numerous ways in which excessive noise in protected areas can have negative impacts on health and well-being. A closely related goal is to measure how the protection of natural sounds can offer much-needed opportunities for cognitive restoration and recovery from stress. More work has been done in the field to demonstrate the negative effects of excessive noise on humans and wildlife; less work has attempted to quantify the psychological and physiological benefits that accrue from preserving natural soundscapes (particularly in protected area settings). Thus, this study intended to look for differences between physiological responses to natural and anthropogenic stimuli. It was hypothesized that greater changes would be detected in response to the anthropogenic stimuli, based on the psychophysiological literature describing the link between affective states and autonomic nervous system reactivity (Bradley \& Lang, 2000).

Stress recovery. Some pioneering research has attempted to document the health benefits of natural environments, focusing on the visual characteristics of the environment. Building on earlier quasi-experimental research that showed that surgical patients in hospital rooms that had windows with views of nature had better health outcomes than patients in rooms without nature views (Ulrich, 1984), Ulrich et al. (1991) used an experimental stressor to induce physical stress (indicated by physiological arousal and negative affect) in laboratory participants. They subsequently recorded the extent and time course of the participants' physiological and affective recuperation when viewing either a natural or urban scene. The results confirmed a faster and more complete recovery from stress and a negative affective state following exposure 
to natural settings. This experiment provided biologically-based evidence that it is possible to quantify the restorative aspects of nature. Subsequent research has adapted Ulrich et al.’s approach using auditory stimuli and found similar benefits of natural acoustic environments in stress recovery (Alvarsson, Wiens, \& Nilsson, 2010).

Cognitive restoration. A related, but distinct, theory highlights the role of renewal of attentional resources, instead of stress recovery, in facilitating restoration. Attention restoration theory (Kaplan \& Kaplan, 1989) identifies four central factors that contribute to a restorative experience by allowing attentional capacities depleted from stimulus overload to be renewed. Restoration requires psychological distance from the sources of everyday mental effort (being away), effortless attention directed by interest (fascination), coherently ordered environments of a large scale (extent), and congruence between interests and the demands of the environment (compatibility). With these four factors present, restorative experiences are more likely. Moreover, the factors are typically found in great abundance in natural environments (Kaplan \& Kaplan, 1989).

An underlying component of the restoration theories is that human response to the environment is rooted in evolutionary influences. Much like E. O. Wilson’s (1984) biophilia hypothesis, the idea is that we are biologically adapted and hardwired to respond to elements of our natural environment in very specific ways, based on evolutionary forces. The restoration theories attempt to identify those characteristics of the natural environment that produce beneficial responses, often at a subconscious, physiological level. Because humans developed as a part of the natural environment, the theory speculates, we are innately attracted to natural features that once held survival implications. In modern times, survival may be a weaker motivator of behavior, but the prehistoric impulses still remain. Protected areas offer certain 
natural characteristics - soundscapes presumably among them - that humans instinctively respond to in a positive way, and that the built environment will never be able to replicate. These positive responses to the natural environment are likely to manifest at a deeply rewarding and beneficial level of the human biology, as well, with improvements to physical health and psychological well-being a result.

Previous research has taken these theories into field settings. One ambitious study obtained measures of ambulatory blood pressure, affect, and attention from participants with varying needs for restoration following demanding tasks (Hartig, Evans, Jamner, Davis, \& Garling, 2003). Participants were tested in either a nature reserve or urban setting, sitting or walking. The results confirmed the hypothesis that natural surroundings facilitate physical and psychological restoration for city dwellers. And although the relationship is likely complex, there is evidence that both physiological and attentional restoration processes contribute in a complementary way to restorative experiences. The authors emphasize the public health value of providing restorative environments, especially in times of urbanization, skyrocketing health care costs, and declining environmental quality. “As with regular sleep, regular access to restorative environments can interrupt processes that negatively affect health and well-being in the shortand long-term” (Hartig et al., 2003, p. 122). Whether the exact mechanism underlying restoration is more closely linked to psychophysiological stress recovery or renewal of attentional capacities - or some kind of symbiosis of the two processes - it is reasonable to conclude that protected areas offer great potential for restorative experiences. This is a positive benefit that is worthy of the greatest protection efforts. Maintaining the character of protected area soundscapes as closely as possible to natural conditions is a critical step in assuring that the 
public can continue to find much-needed psychological and physical restoration in their protected areas.

Linking the physiological and psychological. As early as the $19^{\text {th }}$ century, philosopher and psychologist William James theorized that emotions originated from somatovisceral signals from changes in the body. "No shade of emotion, however slight, should be without a bodily reverberation as unique, when taken in its totality, as is the mental mood itself” (James, 1890, p. 450). Despite the refinement of this theory over the intervening years, physiological signals have been widely used to make inferences about a range of psychological properties (Cacioppo \& Tassinary, 1990). Critchley (2009) describes how the field of psychophysiology is based on the assumption of embodiment of the human mind - that is, there is a reciprocal relationship between mental processing (including thoughts, feelings, and behavior) and the physiological state of the body. Bradley and Lang (2000) provide evidence for a direct link between the physiological and psychological in their work with affective pictures and sounds: "When people look at affective pictures, reliable patterns of physiological change are found in somatic, visceral, and central systems that vary significantly with reports of affective valence and arousal” (pg. 204).

While there are many challenges to making assumptions about simple connections between physiological data and psychological states, physiological measures like electrodermal activity and heart rate have been commonly used as markers of peripheral determinants of affective states (Cacioppo \& Tassinary, 1990). Norman et al. (2011) argue that recent progress in both theoretical and technological approaches have encouraged new conceptualizations of affective mechanisms and their neural underpinnings. In addition, a negativity bias has been theorized such that humans demonstrate a greater sensitivity to - and faster processing of - 
negative or threatening stimuli relative to positive or rewarding stimuli (Ito \& Cacioppo, 2000).

Thus, this study aimed to detect changes in physiological functioning in response to

hypothesized positive (natural sounds) and negative (motorized sounds) stimuli, with the expectation of observing greater effects from the motorized stimuli. In so doing, it was assumed that affective feelings are strongly linked to autonomic and visceral bodily responses, and that such responses differ between subjective affective states (Critchley, 2009).

\section{Methods}

Physiological data were collected using a BIOPAC MP150 data acquisition system (BIOPAC Systems, Inc., Camino Goleta, CA) running AcqKnowledge 3.9.1 software. After providing informed consent and prior to completing the baseline surveys, four general purpose disposable EL503 BIOPAC electrodes were applied to participants’ extremities. Before applying the electrodes, the skin was cleansed with an alcohol wipe and allowed to dry. The electrodes were applied to the distal ends of digits 2 and 3, ventral side of the wrist, and ankle (posterior to the medial malleolus) on the non-dominant side. Electrodes were taped to the skin surface to improve contact and adhesion. Galvanic skin response (GSR) and electrocardiogram (ECG) data were obtained on a continuous basis, at an acquisition rate of 100 samples per second, providing a temporal resolution of $10 \mathrm{~ms}$. GSR was measured by assessing changes in skin surface perspiration by means of a weak electrical current passed between the electrodes. Heart rate (HR) was calculated from ECG data, based on the length of time between QRS complexes in the ECG waveform.

Physiological data were obtained for a baseline period of at least 5 minutes, while participants completed baseline surveys, and throughout the landscape assessment phase of the experiment. Each sound condition (i.e., the start of the motorcycle stimulus block or the start of 
the Denali natural sounds stimulus block) was flagged in the physiological recording to facilitate subsequent data analysis. Following the landscape assessments, participants completed a brief questionnaire eliciting attitudes and beliefs about motorized vehicle use in protected areas. A second 5-minute baseline period of physiological monitoring was acquired during and subsequent to this questionnaire. The total duration of continuous physiological recording was approximately 30 minutes.

GSR and HR data were extracted for each 3-minute sound condition, as well as the 5minute (or more) baseline periods before and after the landscape assessments. Thus, a total of 8 GSR and 8 HR measurements were obtained for each participant (6 sound conditions plus 2 baseline periods). HR values (mean beats per minute, BPM) were averaged over the full 3 minutes for each sound condition. Approximately 3 minutes of data were averaged for the separate baseline periods at the beginning and end of the experiment to be consistent with the interval of data used in the sound conditions. GSR values (in volts) were analyzed over the same time periods as HR by calculating the area under the curve during each condition and correcting for the duration of the timeframe being analyzed. The resulting measurement was in the unit of volts per second.

Waveforms from each sound condition were inspected visually for unacceptable levels of noise in the data, and measurement values were excluded from analysis for conditions with high levels of noise or data acquisition artifacts. This procedure resulted in 52 of the possible 608 individual conditions (76 completed participants multiplied by 8 conditions per participant) being excluded from physiological analysis. Conditions were eliminated from the final analysis as follows: 9 from the first baseline period, 8 Denali natural sounds conditions, 5 Glacier natural sounds conditions, 8 Yellowstone natural sounds conditions, 4 propeller plane conditions, 4 
motorcycle conditions, 5 snowmobile conditions, and 9 from the second baseline period. The remaining values were averaged across participants to obtain a grand mean for each condition for both HR and GSR. Difference scores were also calculated by subtracting the values from each condition from the pre- and post-baseline values. Difference scores were converted to percentages to measure the percent change from baseline, as an alternative outcome measure. For simplicity, only the percent change scores relative to the initial baseline period are reported below. Additional conditions were necessarily removed from the analysis for the percent change measures, where the baseline data obtained were unreliable.

\section{Results}

Physiological data are shown in Tables 11 (mean scores) and 12 (percent change). HR (in BPM) and GSR (in volts/sec) were averaged across participants and are displayed for each sound condition and baseline period. Mean GSR was 0.49 for the natural conditions (Denali = 0.48 , Glacier $=0.48$, Yellowstone $=0.48$ ) and 0.51 for the motorized conditions (propeller $=$ 0.50 , motorcycle $=0.49$, snowmobile $=0.52$ ). Mean GSR for the initial baseline period was 0.45. Mean HR was 74.0 for the natural conditions $($ Denali $=73.3$, Glacier $=73.9$, Yellowstone $=73.8$ ) and 74.1 for the motorized conditions (propeller $=74.0$, motorcycle $=74.0$, snowmobile = 73.8). Mean HR for the initial baseline period was 76.9. (Note that the mean GSR and HR values for the combined natural and motorized conditions were greater than the individual means due to differences in the way that missing data were handled for the combined and individual conditions.) The average percent change in GSR from baseline for the natural conditions was 10.6\% $($ Denali $=10.1 \%$, Glacier $=13.4 \%$, Yellowstone $=8.5 \%)$ and $14.2 \%$ for the motorized conditions $($ propeller $=15.2 \%$, motorcycle $=11.7 \%$, snowmobile $=15.6 \%)$. The average percent change in HR from baseline for the natural conditions was $-4.8 \%$ (Denali $=-5.0 \%$, Glacier $=-$ 
$4.8 \%$, Yellowstone $=-4.6 \%$ ) and $-4.2 \%$ for the motorized conditions (propeller $=-4.1 \%$,

motorcycle $=-4.3 \%$, snowmobile $=-4.3 \%)$.

Table 11. Summary physiological data for baseline and sound conditions

\begin{tabular}{ccc}
\hline Condition & $\begin{array}{c}\text { GSR (volts per } \\
\text { second) }\end{array}$ & $\begin{array}{c}\text { HR (mean beats } \\
\text { per minute) }\end{array}$ \\
\hline Baseline & 0.45 & 76.9 \\
Natural (DENA) & 0.48 & 73.3 \\
Natural (GLAC) & 0.48 & 73.9 \\
Natural (YELL) & 0.48 & 73.8 \\
Propeller & 0.50 & 74.0 \\
Motorcycle & 0.49 & 74.0 \\
Snowmobile & 0.52 & 73.8 \\
\hline NATURAL & 0.49 & 74.0 \\
MOTORIZED & 0.51 & 74.1 \\
\hline
\end{tabular}

Table 12. Percent change physiological data for baseline and sound conditions

\begin{tabular}{ccc}
\hline Condition & GSR (\% change) & HR (\% change) \\
\hline Natural (DENA) & 10.1 & -5.0 \\
Natural (GLAC) & 13.4 & -4.8 \\
Natural (YELL) & 8.5 & -4.6 \\
Propeller & 15.2 & -4.1 \\
Motorcycle & 11.7 & -4.3 \\
Snowmobile & 15.6 & -4.3 \\
\hline NATURAL $^{1}$ & 10.6 & -4.8 \\
MOTORIZED $^{2}$ & 14.2 & -4.2
\end{tabular}

${ }^{1}$ NATURAL = average of 3 natural conditions (DENA, GLAC, YELL)

${ }^{2}$ MOTORIZED = average of 3 motorized conditions (propeller, motorcycle, snowmobile)

Differences between physiological responses in the baseline and combined sound conditions were explored by paired samples $t$-tests (Tables 13 and 14). GSR was significantly different between baseline $(M=0.45, S D=0.08)$ and natural sounds $(M=0.49, S D=0.08)$ conditions, $t(66)=2.57, p<.05$. HR was also significantly different between baseline $(M=$ 
$76.9, S D=12.2)$ and natural sounds $(M=73.2, S D=10.6)$ conditions, $t(66)=7.27, p<.001$. Significant differences also emerged when comparing the baseline and combined motorized conditions. GSR was significantly lower at baseline than in the motorized sounds $(M=0.50, S D$ $=0.08)$ conditions, $t(66)=4.06, p<.001$. By contrast, HR was significantly higher at baseline than in the motorized sounds $(M=73.5, S D=10.8)$ conditions, $t(66)=6.60, p<.001$. When comparing between the combined natural and combined motorized sounds conditions, no significant differences were apparent in the physiological measures. GSR was not significantly higher in the motorized conditions than in the natural conditions, $t(72)=1.33, p=.19$ ). HR was nearly identical between the two categories of sound conditions, $t(72)=0.59, p=.56$ ).

Table 13. Paired samples $t$-tests between baseline and combined natural and motorized sound conditions for GSR

\begin{tabular}{cccccc}
\hline Variable & Mean & $S D$ & $\mathrm{df}$ & $t$ & $P$ \\
\hline Baseline & 0.45 & 0.08 & 66 & 2.57 & $.013^{*}$ \\
NATURAL & 0.49 & 0.08 & 66 & & \\
Baseline & 0.45 & 0.08 & & \multirow{2}{*}{6.06} & $<.001^{*}$ \\
MOTORIZED & 0.50 & 0.08 & & & \\
\hline
\end{tabular}

* Significant at $p<.05$

Table 14. Paired samples $t$-tests between baseline and combined natural and motorized sound conditions for HR

\begin{tabular}{cccccc}
\hline Variable & Mean & $S D$ & $\mathrm{df}$ & $t$ & $P$ \\
\hline Baseline & 76.91 & 12.15 & \multirow{2}{*}{66} & 7.27 & $<.001^{*}$ \\
NATURAL & 73.21 & 10.57 & & & \\
Baseline & 76.91 & 12.15 & \multirow{2}{*}{66} & 6.60 & $<.001^{*}$ \\
MOTORIZED & 73.52 & 10.80 & & & \\
\hline
\end{tabular}

* Significant at $p<.05$

Paired samples $t$-tests were also performed between corresponding conditions (i.e., between the natural and motorized sound conditions for each park, Tables 15 and 16). There was a significant difference in GSR between the natural sounds $(M=0.48, S D=0.10)$ and 
snowmobile $(M=0.52, S D=0.15)$ conditions for the Yellowstone scenes, $t(68)=2.12, p<.05$. However, there were no other significant differences between the other conditions. Interestingly, and counter to what would be expected, there were no significant correlations between GSR and HR in any of the sound conditions or baseline periods $(R \leq .16, p \geq .18)$.

Table 15. Paired samples $t$-tests between natural and motorized conditions for GSR

\begin{tabular}{cccccc}
\hline Variable & Mean & $S D$ & $\mathrm{df}$ & $t$ & $P$ \\
\hline Natural (DENA) & 0.48 & 0.11 & 67 & 1.28 & .206 \\
Propeller & 0.50 & 0.12 & & & \\
Natural (GLAC) & 0.48 & 0.10 & & & \\
Motorcycle & 0.49 & 0.13 & 67 & 0.55 & .586 \\
Natural (YELL) & 0.48 & 0.10 & & & \\
Snowmobile & 0.52 & 0.15 & 68 & 2.12 & $.037 *$ \\
\hline NATURAL & 0.49 & 0.09 & \multirow{2}{*}{72} & 1.33 & .187 \\
MOTORIZED & 0.51 & 0.08 & & &
\end{tabular}

* Significant at $p<.05$

Table 16. Paired samples $t$-tests between natural and motorized conditions for HR

\begin{tabular}{cccccc}
\hline Variable & Mean & $S D$ & $\mathrm{df}$ & $t$ & $P$ \\
\hline Natural (DENA) & 73.29 & 11.06 & 67 & 1.60 & .115 \\
Propeller & 73.95 & 11.82 & & & \\
Natural (GLAC) & 73.89 & 11.69 & & & \\
Motorcycle & 74.05 & 11.69 & 67 & 0.36 & .719 \\
Natural (YELL) & 73.83 & 11.23 & & & \\
Snowmobile & 73.81 & 11.14 & 68 & 0.07 & .947 \\
\hline NATURAL & 73.97 & 11.27 & 72 & 0.59 & .560 \\
MOTORIZED & 74.13 & 11.34 & & & \\
\hline
\end{tabular}

When comparing the physiological data with the results from the PANAS (Tables 17 and 18), some significant correlations emerge. This comparison allows us to look for congruence between bodily arousal and affective appraisal and interpretation. The change in positive affect from baseline following the Glacier natural sounds condition was negatively correlated with HR 
$(r=-.57, p=.05)$. This means that for those participants who received the Glacier natural sounds condition first $(n=12)$, higher reported positive affect following the natural sounds condition relative to baseline was associated with higher heart rate. For those participants who received the Glacier natural sounds condition second $(n=12$, following the motorcycle condition), change in positive affect following the natural sounds condition (relative to the motorcycle condition) was positively correlated with GSR $(r=.64, p<.05)$. In this case, an increase in positive affect from the motorcycle condition to the natural sounds condition was associated with a decrease in GSR. The change in positive affect from baseline following the Yellowstone natural sounds condition was negatively correlated with $\operatorname{HR}(r=-.67, p<.05)$. This means that for those participants who received the Yellowstone natural sounds condition first ( $n=11)$, greater reported positive affect following the natural sounds condition relative to baseline was associated with higher heart rate.

Table 17. Significant correlations between GSR and PANAS

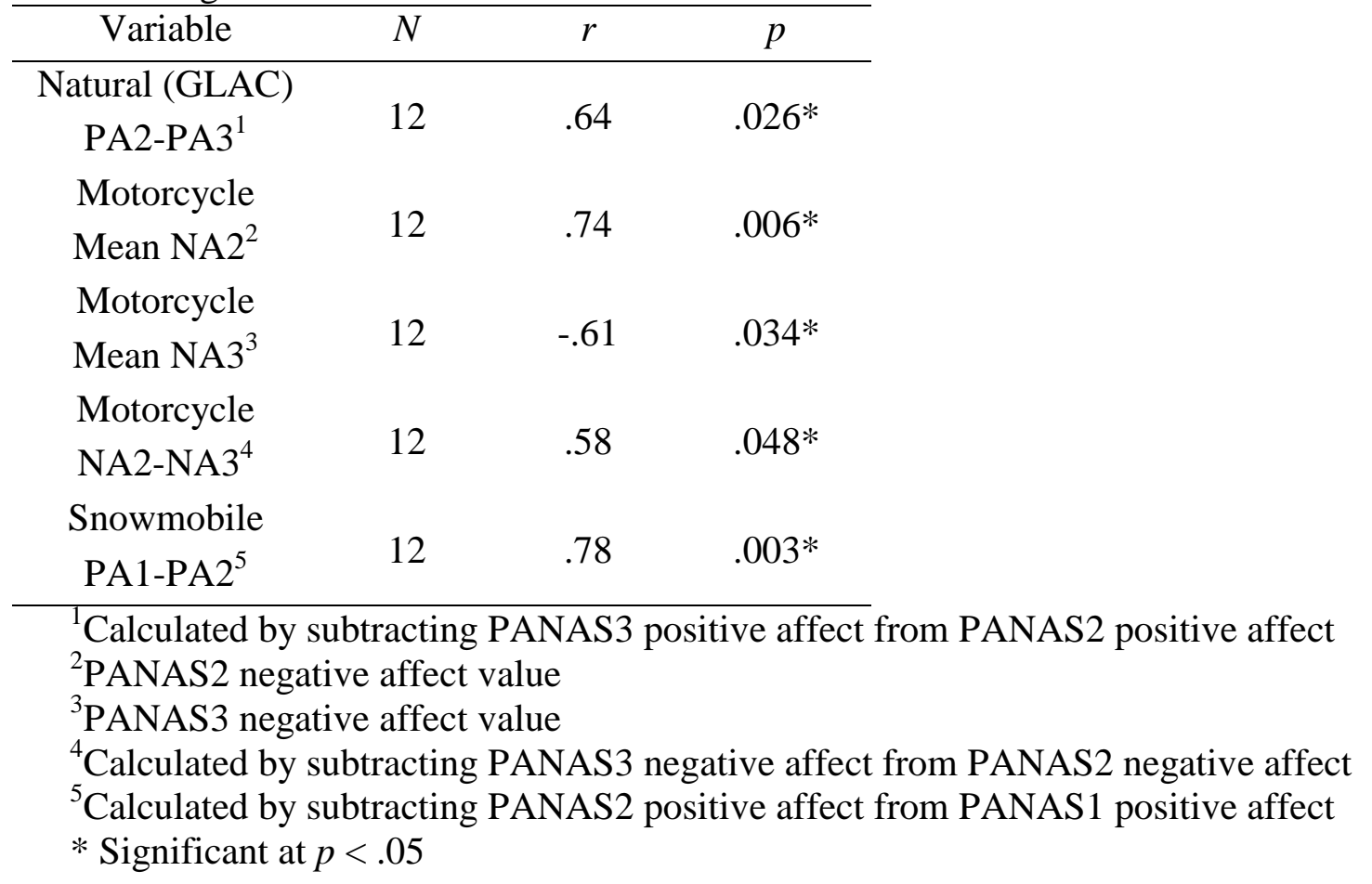


Table 18. Significant correlations between HR and PANAS

\begin{tabular}{cccc}
\hline Variable & $N$ & $r$ & $p$ \\
\hline Natural (GLAC) & 12 & -.57 & .051 \\
PA1-PA2 & & & \\
Natural (YELL) & & & \\
PA1-PA2 & 11 & -.67 & $.025^{*}$ \\
Propeller & & & \\
PA2-PA3 $^{2}$ & 11 & .73 & $.011^{*}$
\end{tabular}

${ }^{1}$ Calculated by subtracting PANAS2 positive affect from PANAS1 positive affect

${ }^{2}$ Calculated by subtracting PANAS3 positive affect from PANAS2 positive affect

* Significant at $p<.05$

Negative affect for those participants who received the motorcycle condition first $(n=$ 12) was positively correlated with GSR $(r=.74, p<.05)$. For those participants who received the motorcycle condition second ( $n=12$, following the Glacier natural sounds condition), negative affect following the motorcycle condition was negatively correlated with GSR $(r=-.61$, $p<.05$ ). For those same participants, change in negative affect following the motorcycle condition (relative to the natural sounds condition) was positively correlated with GSR ( $r=.58$, $p<.05)$. In this case, an increase in negative affect from the natural sounds condition to the motorcycle condition was associated with a decrease in GSR. For those participants who received the propeller condition second ( $n=11$, following the Denali natural sounds condition), change in positive affect following the propeller condition (relative to the natural sounds condition) was positively correlated with $\operatorname{HR}(r=.73, p<.05)$. In this case, a decrease in positive affect from the natural sounds condition to the propeller condition was associated with an increase in HR. Finally, the change in positive affect from baseline following the snowmobile condition was positively correlated with GSR $(r=.78, p<.01)$. This signifies that for those participants who received the snowmobile condition first $(n=12)$, lower reported positive affect 
following the snowmobile condition relative to baseline was associated with increased electrodermal activity.

When the physiological results were compared to the psychological questionnaires (NSS and NEP), only one significant finding was observed (Table 19). Mean NSS was negatively correlated with GSR in the Glacier natural sounds condition $(r=-.25, p<.05)$. Thus, higher scores on noise sensitivity were associated with lower GSR values measured during the Glacier natural sounds condition. No other significant correlations were obtained between any of the other conditions and the NEP or NSS.

Table 19. Significant correlations between physiological data and psychological scales

\begin{tabular}{cccc}
\hline Variable & $N$ & $r$ & $p$ \\
\hline Mean NSS & 69 & -.25 & $.042^{*}$ \\
Natural (GLAC) GSR & & & \\
\hline
\end{tabular}

* Significant at $p<.05$

Physiological results were also compared to the composite and difference scores from the landscape assessments. Three significant findings were obtained from this comparison (Table 20). First, in the Glacier natural sounds condition, the composite landscape assessment score (the average of the 8 individual aesthetic dimensions) was positively correlated with HR ( $r=.26$, $p<.05$ ). Second, in the motorcycle condition, the landscape assessment difference score (i.e., when the average of the landscape assessments from the motorcycle condition was subtracted from the average from the Glacier natural sounds condition) was positively correlated with HR ( $r$ $=.27, p<.05)$. Thus, the greater the decrease in landscape assessment ratings from the natural condition to the motorcycle condition, the greater the observed HR during the latter condition. Third, when the landscape assessment composite scores were further combined into natural and motorized sounds categories, a significant positive correlation was obtained between the natural sounds composite score and mean HR from the motorized sounds conditions $(r=.24, p<.05)$. 
The correlation between the natural sounds composite score and mean HR from the natural sounds conditions suggested a near-significant statistical trend $(r=.22, p=.06)$.

Table 20. Significant correlations between physiological data and landscape assessments

\begin{tabular}{cccc}
\hline Variable & $N$ & $r$ & $p$ \\
\hline $\begin{array}{c}\text { Natural (GLAC) Composite Score } \\
\text { Natural (GLAC) HR }\end{array}$ & 68 & .26 & $.033^{*}$ \\
$\begin{array}{c}\text { Motorcycle Difference Score } \\
\text { Motorcycle HR }\end{array}$ & 71 & .27 & $.025^{*}$ \\
\hline $\begin{array}{c}\text { NATURAL Composite Score } \\
\text { MOTORIZED HR }\end{array}$ & 72 & .24 & $.041^{*}$ \\
$\begin{array}{c}\text { NATURAL Composite Score } \\
\text { NATURAL HR }\end{array}$ & 72 & .22 & .059 \\
\hline
\end{tabular}

* Significant at $p<.05$

\section{Discussion}

Although significant differences in the physiological measures were observed between the baseline and sound conditions, the effect was present for both natural and motorized sound conditions. The observed increase in GSR and decrease in HR from the baseline period to all sound conditions may be more generally attributable to the experimental procedures than to the specific effects of the visual and auditory stimuli presented to the participants. However, despite the fact that no significant differences were detected in either physiological measurement between the combined natural sounds and motorized sounds conditions, there was a significant finding in the snowmobile condition. Unlike the motorcycle and propeller plane sound conditions, GSR was significantly elevated in the snowmobile condition relative to its natural (Yellowstone) baseline condition. No corresponding significant difference in HR was detected in the snowmobile condition. In addition, it was intriguing to find a significant association between elevated HR and reductions in landscape evaluations from the natural baseline in the motorcycle condition. 
Several significant correlations were observed between positive/negative affect scores and physiological measurements. Relatively strong correlations ( $r \geq .57)$ were obtained from each of the motorized noise conditions and for two of the natural sounds conditions. The correlations between mean (and change between conditions in) negative affect and GSR in the motorcycle condition suggest that this physiological measure may be closely related to changes in affective states induced by motorcycle noise in natural environments. However, the direction of the correlations was not consistent between time points, which brings into question the practical significance of these findings. GSR in the snowmobile condition was strongly correlated with change in positive affect from baseline, and HR in the propeller plane condition was significantly correlated with change in positive affect following the second sound condition.

Likewise, a significant correlation was detected between GSR in the Glacier natural condition and change in positive affect following the second sound condition. Significant correlations were also obtained between change in positive affect from baseline and HR in both the Glacier and Yellowstone natural conditions. These results are interesting and potentially very meaningful, as a strong relationship between cognitive appraisal of affective state and more biologically-based indicators of affective state would help validate the significance of the underlying concept - the central role of affect in human responses to noise in protected areas. But a consistent, predictable pattern failed to emerge when comparing self-reported affective measures and physiological responses. Clearly, there is some correspondence between affect and physiological reactivity, as demonstrated by the relatively strong correlations between several of the measures, and across multiple conditions, described above. It may be that the physiological measures provide general information about arousal levels, while the PANAS tells us more about the valence of participants' reactions to the auditory and visual stimuli. However, the direction 
of the correlations was not always suggestive that negative changes in affective appraisal would be accompanied by increases in physiological arousal, as would be expected based on the psychophysiological literature (Bradley \& Lang, 2000).

\section{Managerial Implications}

Physiological arousal was found to be statistically impacted by the presence of snowmobile sound stimuli. Although this effect was not successfully replicated in the motorcycle or propeller plane conditions, it suggests that electrodermal activity may be an appropriate tool to detect the physiological impacts of motorized sounds in laboratory simulations of protected area soundscapes. While not all comparisons between natural and motorized sounds were significantly different, there was a definite trend towards increased physiological arousal in the motorized sounds conditions. It is possible that similar measurements (including changes in blood pressure) obtained in actual protected area settings could yield larger differences between groups. Portable measurements of physiological arousal employed in the field in a continuous, non-invasive, inexpensive manner would likely yield valuable information to protected area managers hoping to quantify the health impacts of different soundscape conditions. The results from this study indicate that such impacts are measurable in a laboratory setting under certain circumstances (i.e., snowmobiles audible in a simulated backcountry setting). Future studies could translate these findings to actual field environments, where the presence of excessive motorized noise may be even more evocative,

stressful, and physiologically arousing than what can be elicited from laboratory participants. 


\section{CONCLUSION}

Taken together, the results from the landscape assessments, affective scales, and physiological monitoring strongly suggest that park visitor experiences and well-being can be protected by providing opportunities to experience natural soundscapes and by limiting anthropogenic noise intrusions. Moreover, the source of the anthropogenic noise may at least partially determine the extent of the impacts. For example, motorcycle noise had the greatest negative impact on the landscape assessments and change in affect from the baseline natural sound conditions. By contrast, snowmobile noise produced elevated electrodermal activity (a measure of autonomic nervous system reactivity that serves as an indicator of bodily arousal) relative to the natural sounds condition - a finding that was not replicated in the other motorized noise conditions.

The benefits of natural sounds are multi-dimensional and complex, encompassing both psychological and physical factors. While more sensitive measures of physiological change would likely allow stronger conclusions to be drawn, the results from the present study suggest that there are negative repercussions from excessive motorized noise in our natural areas. Future laboratory research should extend the methodology presented here to alternative measurements of physiological response, such as blood pressure or skin blood flow. Additionally, these

peripheral measures could be supplemented by data from the central nervous system, including functional brain imaging. When these various modalities are combined with traditional survey methodology and psychological questionnaires, a more comprehensive understanding of the importance of natural soundscapes to human well-being will be possible.

Although the aims of this study precluded the use of measurements from field settings, this carefully controlled laboratory simulation yielded clear impacts to visitor experiences. The 
presence of noise from motorized recreational vehicles reduced positive evaluations of landscape scenes on the order of $30-50 \%$ from the natural sound conditions. Positive affect was reduced approximately $20 \%$ and negative affect increased over 30\% following motorized noise conditions. These effects are quite significant when considering that nothing else varied between the natural and motorized conditions other than the auditory stimuli. The results from this study should embolden and validate park managers' efforts to minimize anthropogenic noise. The simulation demonstrated that psychological and physical well-being could be placed at risk by unregulated levels of motorized noise in protected areas. A broad range of benefits (aesthetic, affective, and physiological) will be maximized when natural soundscapes are preserved for all visitors who seek out their restorative powers. The inter-modality integration of these sources of data will also improve validity for researchers and managers studying the impact of soundscapes on visitor experiences.

\section{Study Limitations}

One potential limitation of this study relates to the fact that participants never saw the source of the sounds, nor were they informed that they would be hearing motorcycles, propeller planes, and snowmobiles, specifically. Some participants may have recognized the sound of the motorcycles, for instance, while others may not. Thus, the impact of the noise in the motorcycle condition may be underestimated for participants who have negative attitudes about motorcycles in protected areas, but who may not have recognized the source of the sound that they experienced. The same is true for the snowmobile condition, which may be less familiar to many participants, and the propeller plane condition, in which participants may not have attributed the noise to a recreational air tour (as opposed to, for example, a commercial aircraft). Feedback from several participants during debriefing suggests that this latter situation may have indeed 
been the case. It may be useful in future studies using this experimental paradigm to instruct participants that the sounds that they hear will all be forms of motorized recreation. Future research should also attempt to clarify whether it is the motorcycle itself that is adversely impacting participants' assessments, or if the effect can be attributed to the fact that motorcycles may symbolize the presence of roads and development (more than propeller planes or snowmobiles).

A second potential limitation is the degree to which results obtained from students in a laboratory setting will generalize to actual park visitors - a very heterogeneous population. Whereas the issues under investigation are presumably highly salient to the majority of national park visitors, they may be of less interest to laboratory participants, and their ratings may reflect a greater indifference than what might be expected in an actual protected area setting. Another related potential limitation is the effectiveness of the simulation. Is it possible to represent the complex, multi-sensory, experience of hiking in the dramatic landscapes portrayed in this study with a PowerPoint slide and an audio recording? It was assumed that by instructing the laboratory participants to imagine they were in those settings, it would be possible to approximate the experience, and, more importantly, individual reactions to the experimental manipulations. With any laboratory simulation, however, there will be some loss of context and authenticity. The combination of laboratory simulations (high internal validity) and onsite fieldwork in protected areas (high external validity) offers the possibility to merge the strengths of these two approaches to form a comprehensive understanding of the psychological processes that influence the experiences of park visitors.

A final potential limitation - related to the experimental design of the present study - is the confounding relationship between the park and source variables. In the interest of 
minimizing participant burden, the number of conditions each participant received was intentionally restricted. Thus, each sound condition was limited to one park only - the actual park in which the audio file was recorded and where there is management interest in that particular sound source. For instance, the motorcycle audio files were only matched with the slides from Glacier (where park management is concerned about the level of motorcycle noise currently experienced by visitors to the park). Participants never responded to the motorcycle sound condition while viewing scenes from either Denali or Yellowstone. As a result, the source of the sound and the park scenes present a potential confound in the design of the study.

With the current design, it was not possible to separate the effects of the sound source from the visual context in which they were experienced. If the scenes from one park were more appealing than those from another park, participants’ responses may have been influenced in a manner independent of the sound condition. However, it was expected that by looking at differences within each park - by comparing the motorized noise sources to their own natural baseline conditions with difference scores and percent changes - the impact of this design feature should be minimized. This particular design was selected to obtain as much information as possible from various common sources of noise in protected areas, while also minimizing participant burden. It was also assumed that a more concise study design would assure that observed physiological responses could be attributed to the auditory stimuli that were under examination and not to general fatigue or lack of interest caused by the study procedures. Results indicated that participants' responses differed only minimally between parks during the natural sounds baseline conditions. 


\section{Lessons Learned/Next Steps}

- Motorized noise degrades aesthetic ratings of landscape quality, with the largest decline produced by motorcycle noise.

- Motorized noise creates impairments in self-reported affective states.

- Motorized noise leads to some detectable changes in physiological arousal, but more sensitive measures are needed.

This thesis has demonstrated the advantage of taking a multi-dimensional approach to the study of soundscape conditions and their associated social impacts. The integration of more cognitive-based landscape assessments with self-reported affective data and physiological responses will improve research validity and allow stronger conclusions to be drawn. The addition of more sensitive peripheral measures (such as blood pressure monitoring) and central nervous system biomarkers obtained from functional brain imaging would further improve this research program. The studies described in this thesis lay the groundwork for future investigations into the wide range of benefits offered by natural soundscapes, as well as the associated loss of psychological and physical benefits when excessive motorized noise intrudes on natural settings. Future social science soundscape research will build upon the methodology that was validated here. Furthermore, connections to acoustic monitoring and modeling of noise propagation in protected areas should be sought to truly represent a systems approach to soundscape conditions. This strategy offers a robust and comprehensive framework for documenting the true impacts to visitors when natural soundscapes are not protected. 


\section{REFERENCES}

Alvarsson, J. J., Wiens, S., \& Nilsson, M. E. (2010). Stress recovery during exposure to nature sounds and environmental noise. International Journal of Environmental Research and Public Health, 7, 1036-1046.

Aydin, Y. \& Kaltenbach, M. (2007). Noise perception, heart rate and blood pressure in relation to aircraft noise in the vicinity of the Frankfurt airport. Clinical Research in Cardiology, 96 (6), 347-358.

Babisch, W., Fromme, H., Beyer, A., \& Ising, H. (2001). Increased catecholamine levels in urine in subjects exposed to road traffic noise: The role of stress hormones in noise research. Environment International, 26, 475-481.

Barber, J. R., Fristrup, K. F., Brown, C. L., Hardy, A. R., Angeloni, L. M., \& Crooks, K. R. (2010). Conserving the wild life therein: Protecting park fauna from anthropogenic noise. Park Science, 26(3), 26-31.

Barber, J. R., Turina, F., \& Fristrup, K. M. (2010). Tolerating noise and the ecological costs of “habituation”. Park Science, 26(3), 24-25.

Barrett, L. F., Quigley, K., Bliss-Moreau, E., Aronson, K. R. (2004). Arousal focus and interoceptive sensitivity. Journal of Personality and Social Psychology, 87, 684-697.

Benfield, J. A., Bell, P. A., Troup, L. J., \& Soderstrom, N. C. (2010). Aesthetic and affective effects of vocal and traffic noise on natural landscape assessment. Journal of Environmental Psychology, 30, 103-111.

Benfield, J. A., Nurse, G. A., Jakubowski, R., Gibson, A. W., Taff, B. D. Newman, P., \& Bell, P. A. (2012). Testing noise in the field: A brief measure of individual noise sensitivity. Environment and Behavior. doi: 10.1177/0013916512454430

Bradley, M. B., \& Lang, P. J. (2000). Affective reactions to acoustic stimuli. Psychophysiology, 37, 204-215.

Cacioppo, J. T., \& Tassinary, L. G. (1990). Inferring psychological significance from physiological signals. American Psychologist, 45 (1), 16-28.

Cohen, S., Evans, G. W., Krantz, D. S., \& Stokols, D. (1980). Physiological, motivational, and cognitive effects of aircraft noise on children. American Psychologist, 35 (3), 231-243.

Creel, S., Fox, J. E., Hardy, A., Sands, J., Garrott, B., \& Peterson, R. O. (2002). Snowmobile activity and glucocorticoid stress responses in wolves and elk. Conservation Biology, 16 (3), 809-814. 
Critchley, H. D. (2009). Psychophysiology of neural, cognitive and affective integration: fMRI and autonomic indicants. International Journal of Psychophysiology, 73, 88094.

Davenport, M. A. \& Borrie, W. T. (2005). The appropriateness of snowmobiling in national parks: An investigation of the meanings of snowmobiling experiences in Yellowstone National Park. Environmental Management, 35 (2), 151-160.

Driver, B. L., Brown, P. J., Stankey, G. H., \& Gregoire, T. G. (1987). The ROS planning system: Evolution, basic concepts, and research needed. Leisure Sciences, 9 (3), 201-212.

Driver, B. L., Nash, R., \& Haas, G. (1987). Wilderness benefits: A state-of-knowledge view. Proceedings, National Wilderness Research Conference: Issues, State of Knowledge, Future Directions. USDA Forest Service General Technical Report INT-220, 294-319.

Driver, B. (2008). Managing to optimize the beneficial outcomes of recreation. State College, PA: Venture Publishing.

Evans, G. W., Bullinger, M., \& Hygge, S. (1998). Chronic noise exposure and physiological response: A prospective study of children living under environmental stress.

Psychological Science, 9 (1), 75-77.

Gramann, J. (1999). The effect of mechanical noise and natural sound on visitor experiences in units of the National Park System. Social Science Research Review, 1 (1), 1-16.

Habib, L., Bayne, E. M., \& Boutin, S. (2007). Chronic industrial noise affects pairing success and age structure of ovenbirds Seiurus aurocapilla. Journal of Applied Ecology, 44, 176184.

Hartig, T., Evans, G. W., Jamner, L. D., Davis, D. S., \& Garling, T. (2003). Tracking restoration in natural and urban field settings. Journal of Environmental Psychology, 23, 109-123.

Henry, J. P. (1992). Biological basis of the stress response. Integrative Physiological and Behavioral Science, 27, 66-83.

Hunter, M. D., Eickhoff, S. B., Pheasant, R. J., Douglas, M. J., Watts, G. R., Farrow, T. F., . . . Woodruff, P. W. (2010). The state of tranquility: Subjective perception is shaped by contextual modulation of auditory connectivity. NeuroImage, 53, 611-618.

Irwin, A., Hall, D. A., Peters, A., \& Plack, C. J. (2011). Listening to urban soundscapes: Physiological validity of perceptual dimensions. Psychophysiology, 48, 258-268.

Ising, H. \& Krupp, B. (2004). Health effects caused by noise: Evidence in the literature from the past 25 years. Noise Health, 6 (22), 5-13.

Ito, T. A., \& Cacioppo, J. T. (2000). Electrophysiological evidence of implicit and explicit categorization processes. Journal of Experimental Social Psychology, 36, 660-676. 
Kaplan, R. \& Kaplan, S. (1989). The experience of nature: A psychological perspective. New York, NY: Cambridge University Press.

Kryter, K. D. (1985). The effects of noise on man (2nd ed.). New York, NY: Academic Press.

Lawler, E. (1973). Motivations in work organizations. Monterey, CA: Brooks/Cole Publishing Company.

Lee, M. E. \& Driver, B. L. (1992). Benefits-based management: A new paradigm for managing amenity resources. Paper presented at: The second Canada/U.S. workshop on visitor management parks, forests, and protected areas. Madison, WI.

Louv, R. (2005). Last child in the woods: Saving our children from nature-deficit disorder. Chapel Hill, NC: Algonquin Books.

Mace, B. L., Bell, P. A., \& Loomis, R. J. (1999). Aesthetic, affective, and cognitive effects of noise on natural landscape assessment. Society \& Natural Resources, 12, 225-242.

Manfredo, M. J., Driver, B. L., \& Brown, P. J. (1983). A test of concepts inherent in experiencebased setting management for outdoor recreation areas. Journal of Leisure Research, 15 (3), 263-283.

Manfredo, M. J. (2008). Who cares about wildlife? Social science concepts for exploring humanwildlife relationships and conservation issues. New York, NY: Springer.

Marin, L. D., Newman, P., Manning, R., Vaske, J. J., \& Stack, D. (2011). Motivation and acceptability norms of human-caused sound in Muir Woods National Monument. Leisure Sciences, 33 (2), 147-161.

Mayne, T. J. (2001). Emotion and health. In T. J. Mayne, \& G. A. Bonanno (Eds.), Emotions: current issues and future directions (pp. 361-397). New York: Guilford Press.

McDonald, C. D., Baumgartner, R. M., \& Iachan, R. (1995). National Park Service aircraft management studies. National Park Service, USDI, Report No. 94-2, Denver, CO.

National Park Service (1916). National Park Service Organic Act. National Park Service, USDI.

National Park Service (2000). Director’s order \#47: Soundscape preservation and noise management. Retrieved from http://www.nps.gov/policy/DOrders/DOrder47.html. Accessed 24 November 2011.

National Park Service (2011). Motorcycle noise in a park environment. NPS report \# IAR 59111. Volpe report \# DOT-VNTSC-NPS-11-15.

National Park Service (2006). National Park Service Management Policies. U.S. Government Printing Office. ISBN 0-16-076874-8. 
Newman, P., Manning, R., \& Trevino, K. (2010). From landscapes to soundscapes: Introduction to the special issue. Park Science, 26 (3), 2-5.

Norman, G. J., Norris, C. J., Gollan, J., Ito, T. A, Hawkley, L. C., Larsen, J. T., . . Berntson, G. G. (2011). Current emotion research in psychophysiology: The neurobiology of evaluative bivalence. Emotion Review, 3 (3), 349-359.

Olmsted, F. L. (1865). The value and care of parks. Report to the Congress of the State of California. [Reprinted in R. Nash, Ed., (1976). The American Environment. Reading, MA: Addison-Wesley, pp. 18-24.]

Owen, M. A., Swaisgood, R. R., Czekala, N. M., Steinman, K. \& Lindburg, D. G. (2004). Monitoring stress in captive giant pandas (Ailuropoda melanoleuca): Behavioral and hormonal responses to ambient noise. Zoo Biology, 23 (2), 147-164.

Park, L., Lawson, S., Kaliski, K., Newman, P., \& Gibson, A. (2010). Modeling and mapping hikers’ exposure to transportation noise in ROMO. Park Science, 26 (3), 59-64.

Parsons, R., Tassinary, L. G., Ulrich, R. S., Hebl, M. R., \& Grossman-Alexander, M. (1998). The view from the road: Implications for stress recovery and immunization. Journal of Environmental Pyschology, 18, 113-139.

Pepper, C. B., Nascarella, M. A., \& Kendall, R. J. (2003). A review of the effects of aircraft noise on wildlife and humans, current control mechanisms, and the need for further study. Environmental Management, 32 (4), 418-432.

Pilcher, E. J., Newman, P., \& Manning, R. E. (2009). Understanding and managing experiental aspects of soundscapes at Muir Woods National Monument. Environmental Management, 43, 425-435.

Quinn, J. L., Whittingham, M. J., Butler, S. J., \& Cresswell, W. (2006). Noise, predation risk compensation and vigilance in the chaffinch Fringilla coelebs. Journal of Avian Biology, 37 (6), 601-608.

Rabin, L. A., Coss, R. G., \& Owings, D. H. (2006). The effects of wind turbines on antipredator behavior in California ground squirrels (Spermophilus beecheyi). Biological Conservation, 131, 410-420.

Rosenberg, E. L. (1998). Level of analysis and the organization of affect. Review of General Psychology, 2, 247-270.

Seligman, M. E. (1975). Helplessness: On depression, development, and death. San Francisco, CA: W. H. Freeman. 
Stack, D. W., Newman, P., Manning, R. E., Aiken, G. D., \& Fristrup, K. M. (2011). Reducing visitor noise levels at Muir Woods National Monument using experiential management. Journal of the Acoustical Society of America, 129 (3), 1375-1380.

Staples, S. L. (1996). Human response to environmental noise: Psychological research and public policy. American Psychologist, 51 (2), 143-150.

Taff, B. D. (2012). Messaging and national park visitor attitudes. (Doctoral Dissertation).

Colorado State University, Fort Collins, CO.

Tarrant, M. A., Haas, G. E., \& Manfredo, M. J. (1995). Factors affecting visitor evaluations of aircraft overflights of wilderness areas. Society \& Natural Resources, 8 (4), 351-360.

Taylor, A. F., \& Kuo, F. E. (2006). Is contact with nature important for healthy child development? State of the evidence. In Spencer, C. \& Blades, M. (Eds.), Children and their environments: Learning, using and designing spaces (pp. 124-140). New York, NY: Cambridge University Press.

Ulrich, R. S. (1984). View through a window may influence recovery from surgery. Science, 224 (4647), 420-421.

Ulrich, R. S., Simons, R. F., Losito, B. D., Fiorito, E., Miles, M. A., \& Zelson, M. (1991). Stress recovery during exposure to natural and urban environments. Journal of Environmental Psychology, 11, 201-230.

Wagar, J. A. (1966). Quality in outdoor recreation. Trends in Parks and Recreation, 3 (3), 9-1 2.

Wells, N. M. \& Evans, G. W. (2003). Nearby nature: A buffer of life stress among rural children. Environment and Behavior, 35 (3), 311-330.

Wilson, E. O. (1984). Biophilia. Cambridge, MA: Harvard University Press. 
APPENDIX A: ELECTRONIC QUESTIONNAIRES 


\section{- lgnore Flow}

\section{Welcome to the survey. Touch the Start}

button to continue

\section{Start}

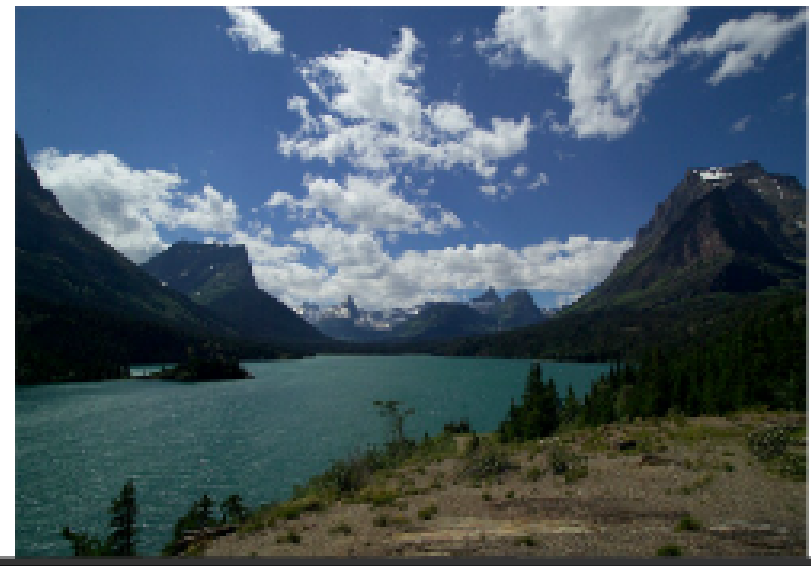

ㅁ.

Figure A-1. Baseline, psychological, and demographic questionnaires. 


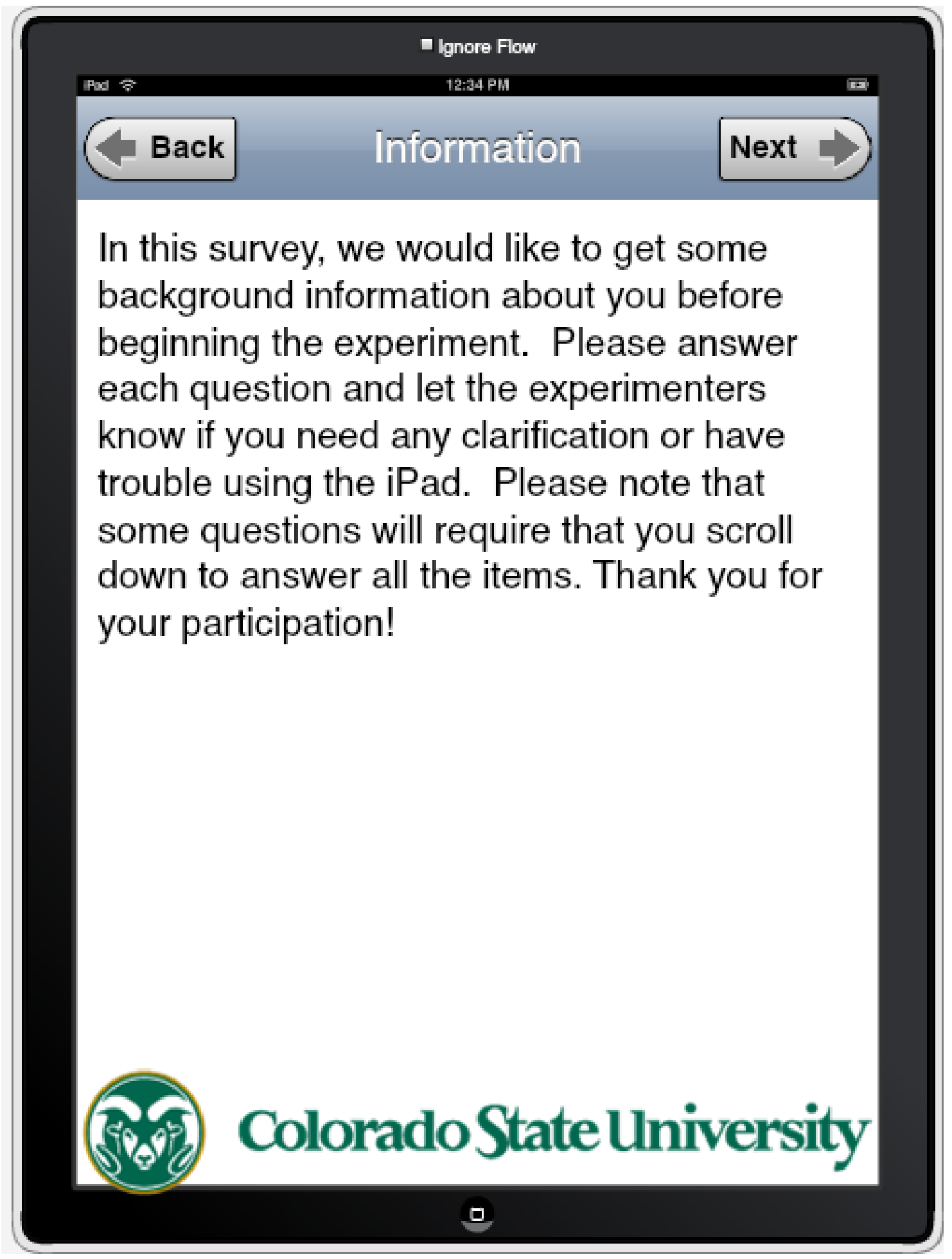

Figure A-1 (continued). Baseline, psychological, and demographic questionnaires. 


\section{Please select the response that best reflects} your answer to each question.

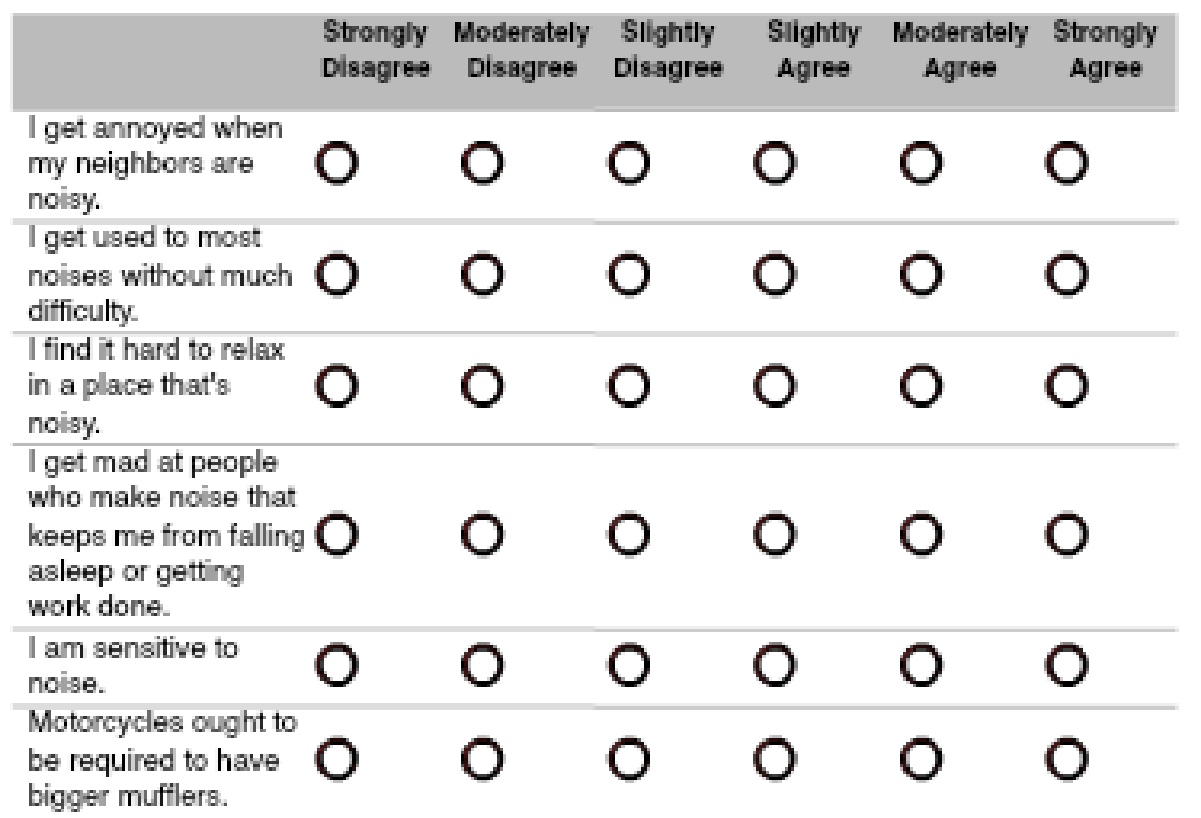

\section{ColoradoState University}

\section{ㅁ.}

Figure A-1 (continued). Baseline, psychological, and demographic questionnaires. 


\section{- lgnore Flow}

Listed below are statements about the relationship between humans and the environment. For each one, please indicate

We are approaching
the limit of the
number of people the
earth can support.
$\begin{aligned} & \text { Humans have the } \\ & \text { right to modify the } \\ & \text { natural environment } \\ & \text { to suit their needs. }\end{aligned}$

Figure A-1 (continued). Baseline, psychological, and demographic questionnaires. 
This scale consists of a number of words that describe feelings and emotions. Indicate to what extent you feel this way RIGHT NOW.

\begin{tabular}{|c|c|c|c|c|c|}
\hline & $\begin{array}{l}\text { Very } \\
\text { or ne }\end{array}$ & A little & Moderately & Quite a bit & Extremely \\
\hline Interested & $\mathrm{O}$ & 0 & 0 & 0 & 0 \\
\hline Distressed & 0 & 0 & 0 & 0 & 0 \\
\hline Excited & $\mathrm{O}$ & $\mathrm{O}$ & $\mathrm{O}$ & $\mathrm{O}$ & $\mathrm{O}$ \\
\hline Upset & 0 & 0 & 0 & 0 & 0 \\
\hline Strong & 0 & $\mathrm{O}$ & $\mathrm{O}$ & $\mathrm{O}$ & $\mathrm{O}$ \\
\hline Guilty & 0 & 0 & 0 & 0 & 0 \\
\hline Scared & $\mathrm{O}$ & $\mathrm{O}$ & $\mathrm{O}$ & $\mathrm{O}$ & $\mathrm{O}$ \\
\hline Hostile & $\mathrm{O}$ & $\mathrm{O}$ & $\mathrm{O}$ & O & 0 \\
\hline Enthusiastic & $\mathrm{O}$ & $\mathrm{O}$ & $\mathrm{O}$ & $\mathrm{O}$ & $\mathrm{O}$ \\
\hline Proud & 0 & 0 & 0 & 0 & 0 \\
\hline Irritable & $\mathrm{O}$ & $\mathrm{O}$ & $\mathrm{O}$ & $\mathrm{O}$ & $\mathrm{O}$ \\
\hline Alert & 0 & 0 & 0 & 0 & 0 \\
\hline Ashamed & $\mathrm{O}$ & $\mathrm{O}$ & $\mathrm{O}$ & $\mathrm{O}$ & $\mathrm{O}$ \\
\hline
\end{tabular}

Figure A-1 (continued). Baseline, psychological, and demographic questionnaires. 


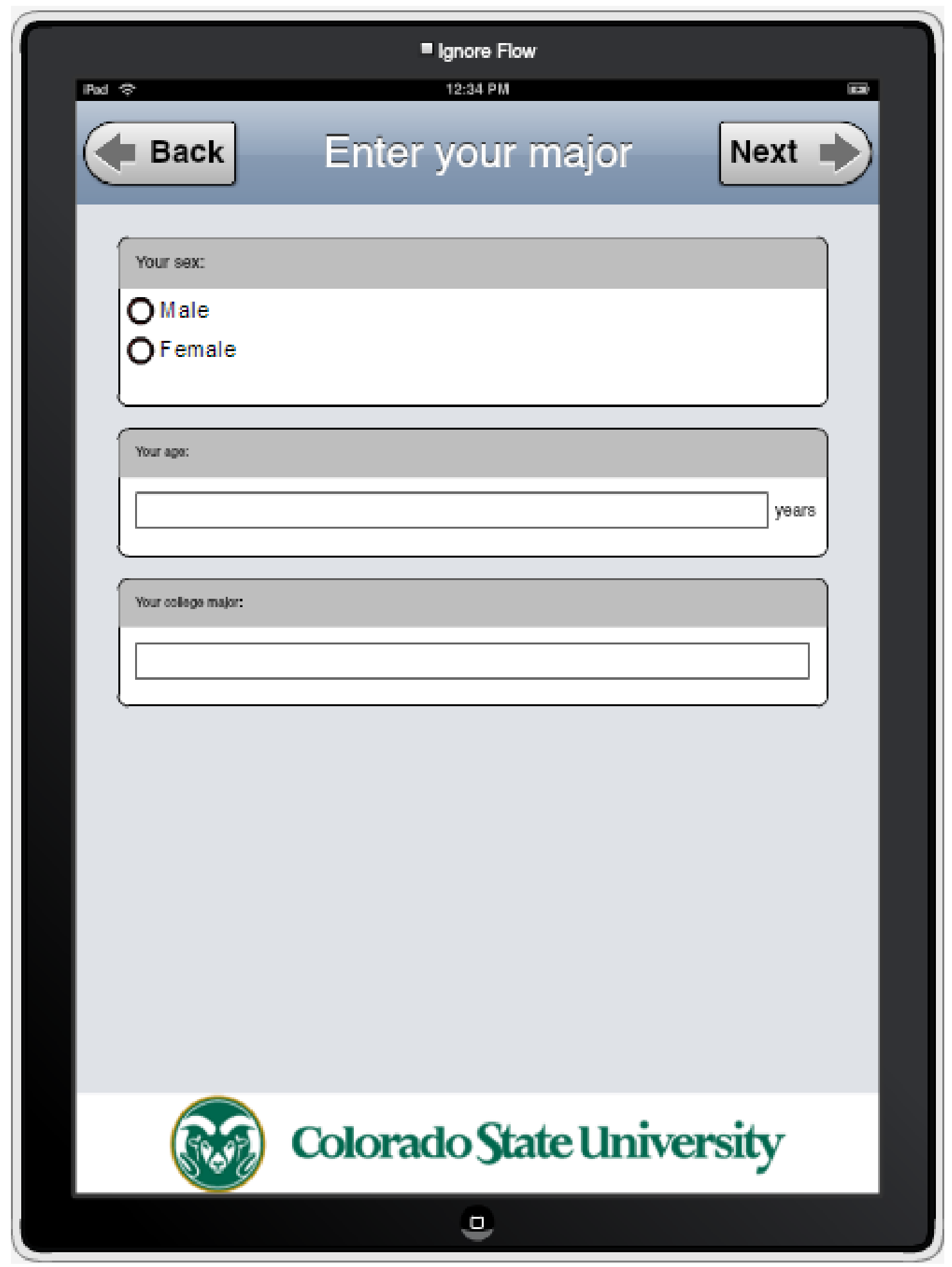

Figure A-1 (continued). Baseline, psychological, and demographic questionnaires. 


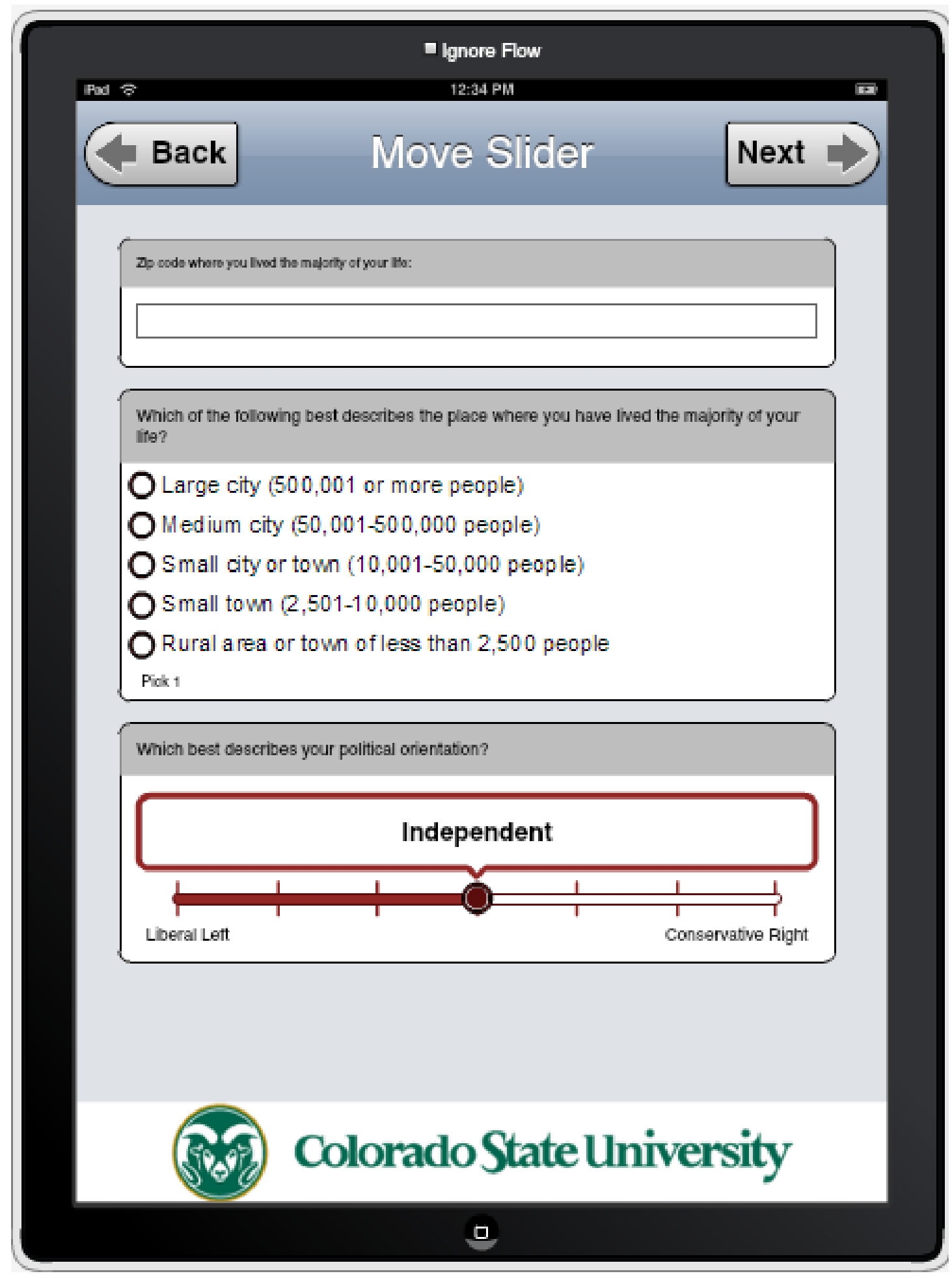

Figure A-1 (continued). Baseline, psychological, and demographic questionnaires. 


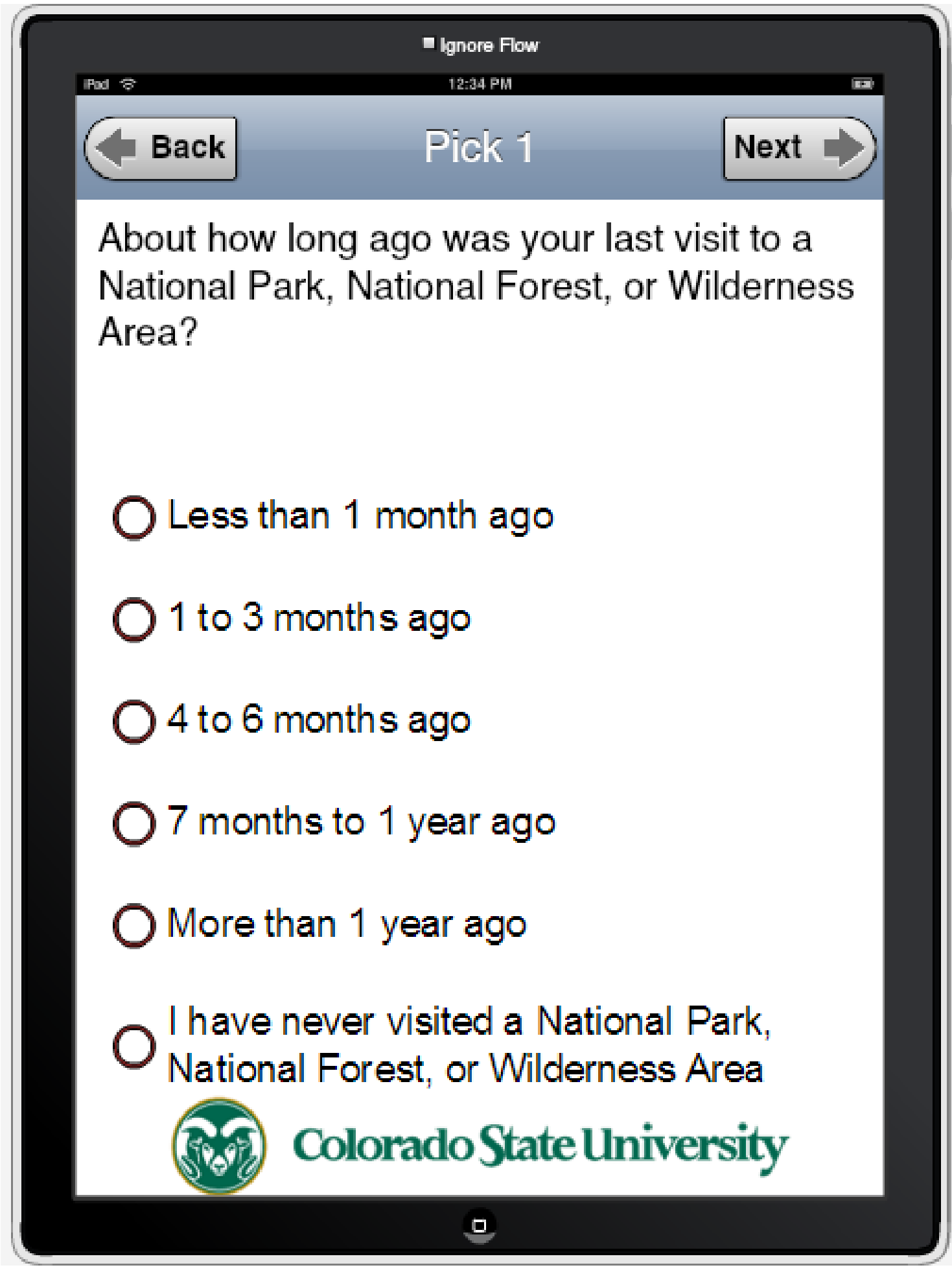

Figure A-1 (continued). Baseline, psychological, and demographic questionnaires. 


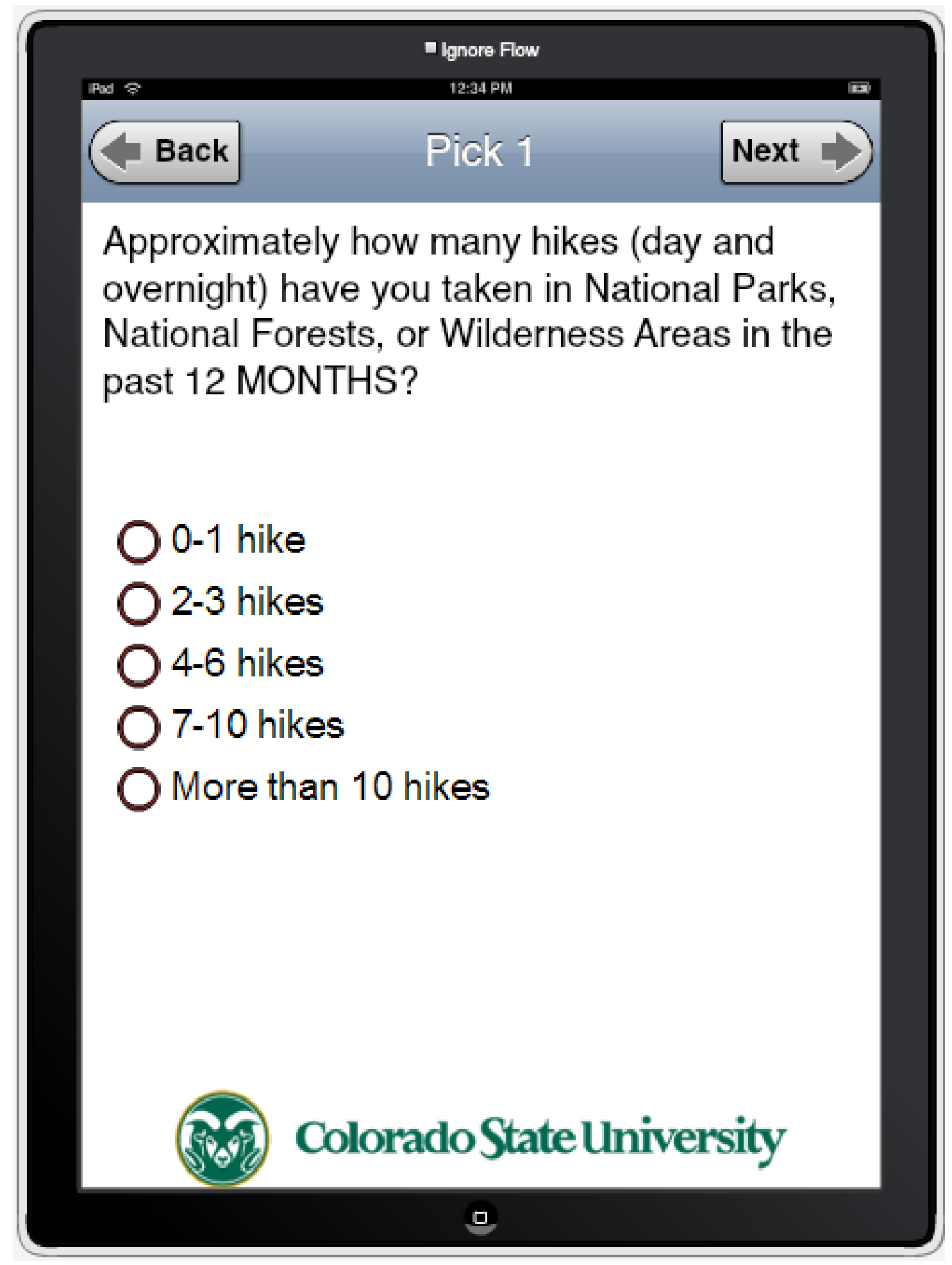

Figure A-1 (continued). Baseline, psychological, and demographic questionnaires. 


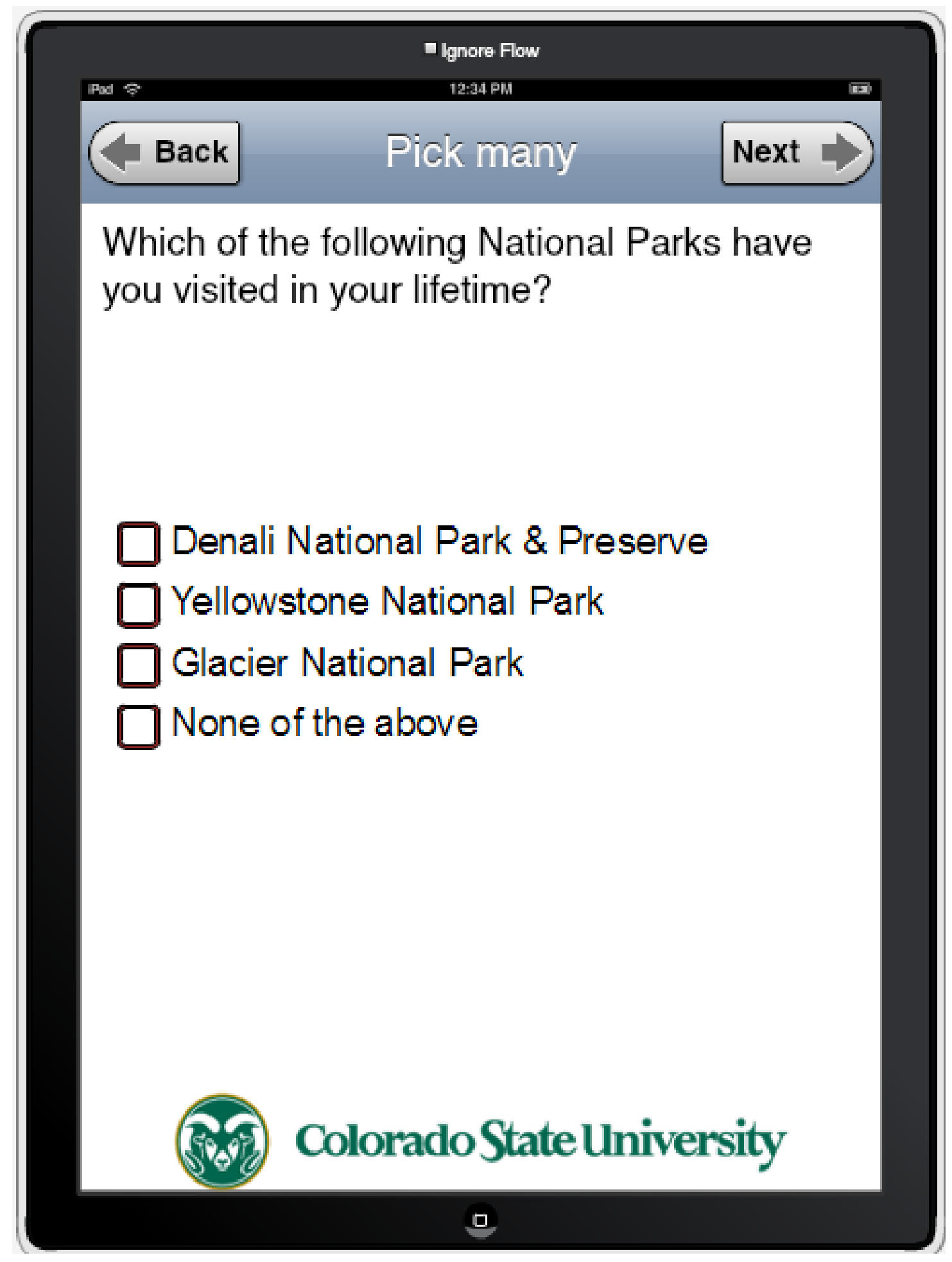

Figure A-1 (continued). Baseline, psychological, and demographic questionnaires. 


\section{Back}

Thank you for completing the survey!

\section{Finish}

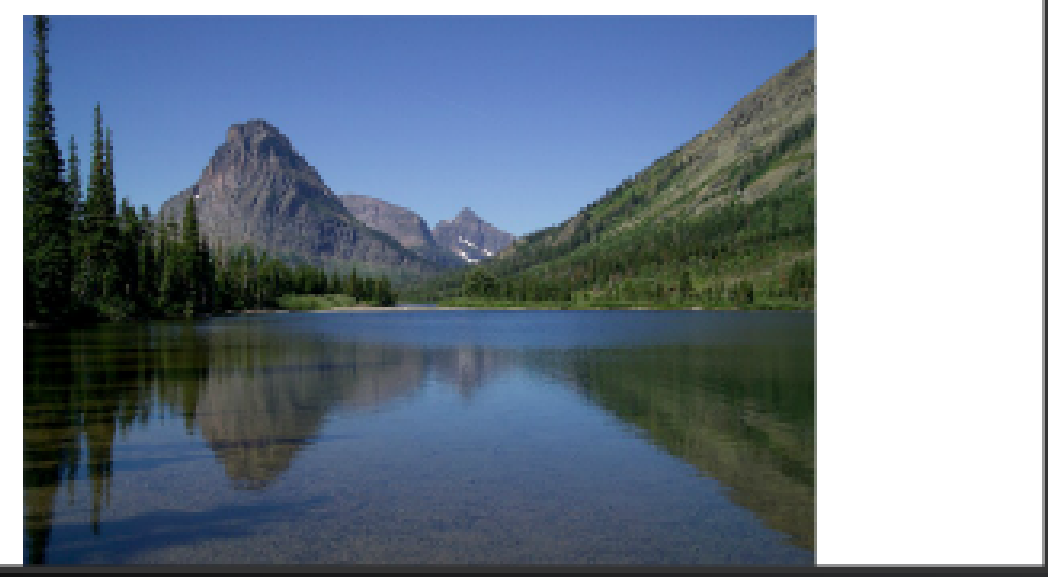

ㅁ.

Figure A-1 (continued). Baseline, psychological, and demographic questionnaires. 


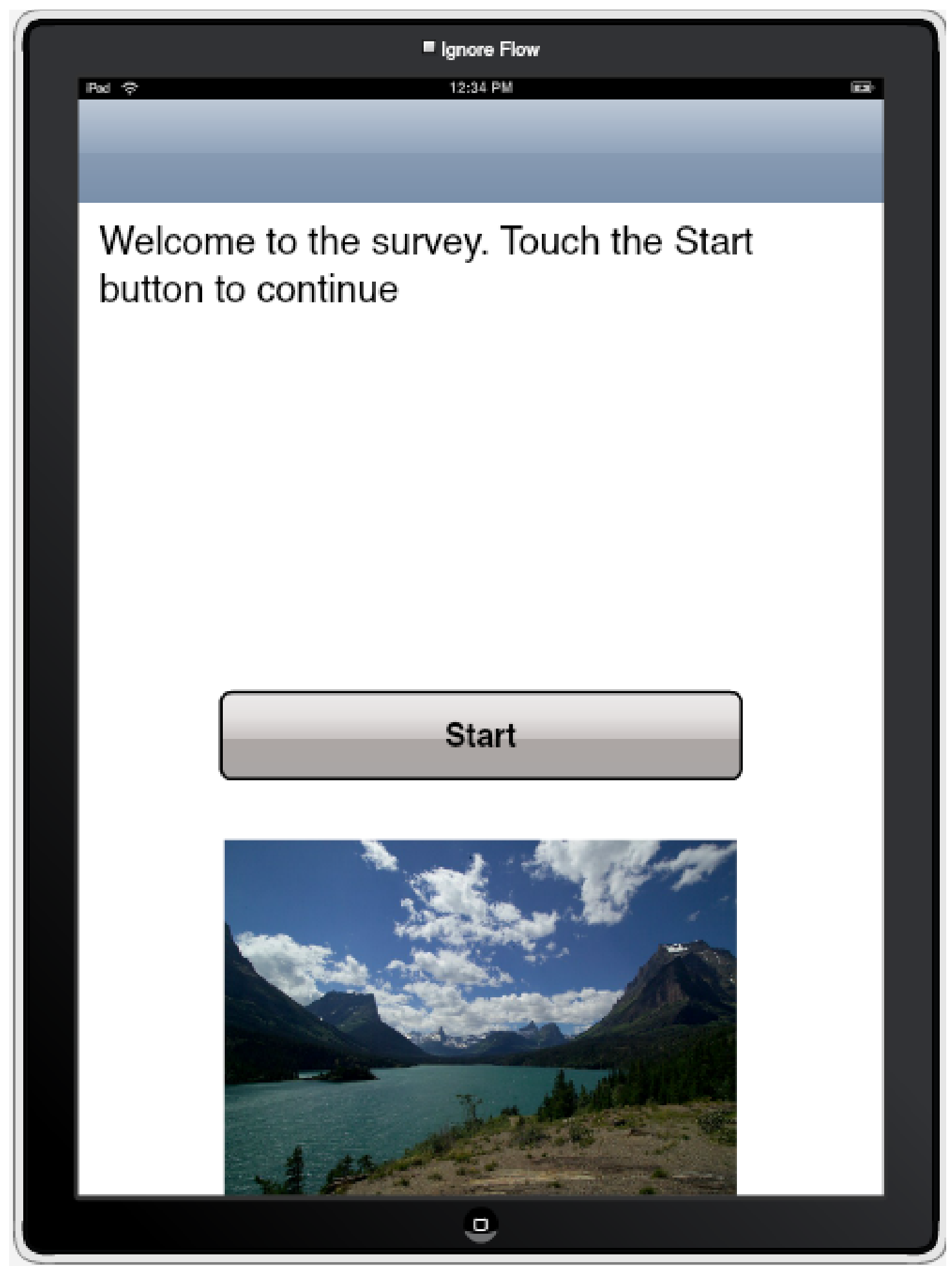

Figure A-2. Landscape assessment and attitude questionnaires. 


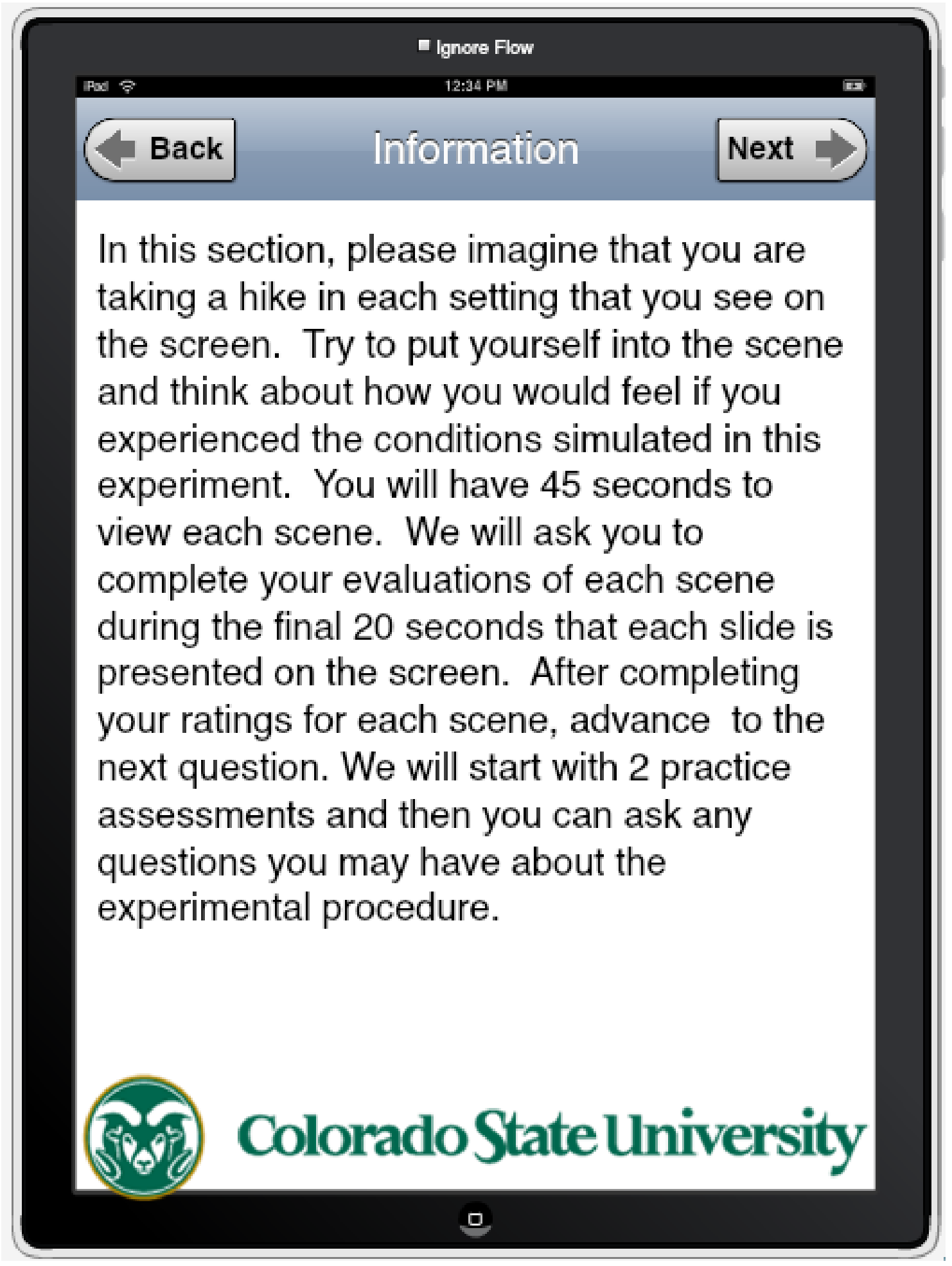

Figure A-2 (continued). Landscape assessment and attitude questionnaires. 


\section{Back}

Next

PRACTICE: Rate the scene you just viewed based on the following dimensions by moving the slider to the line that best represents your

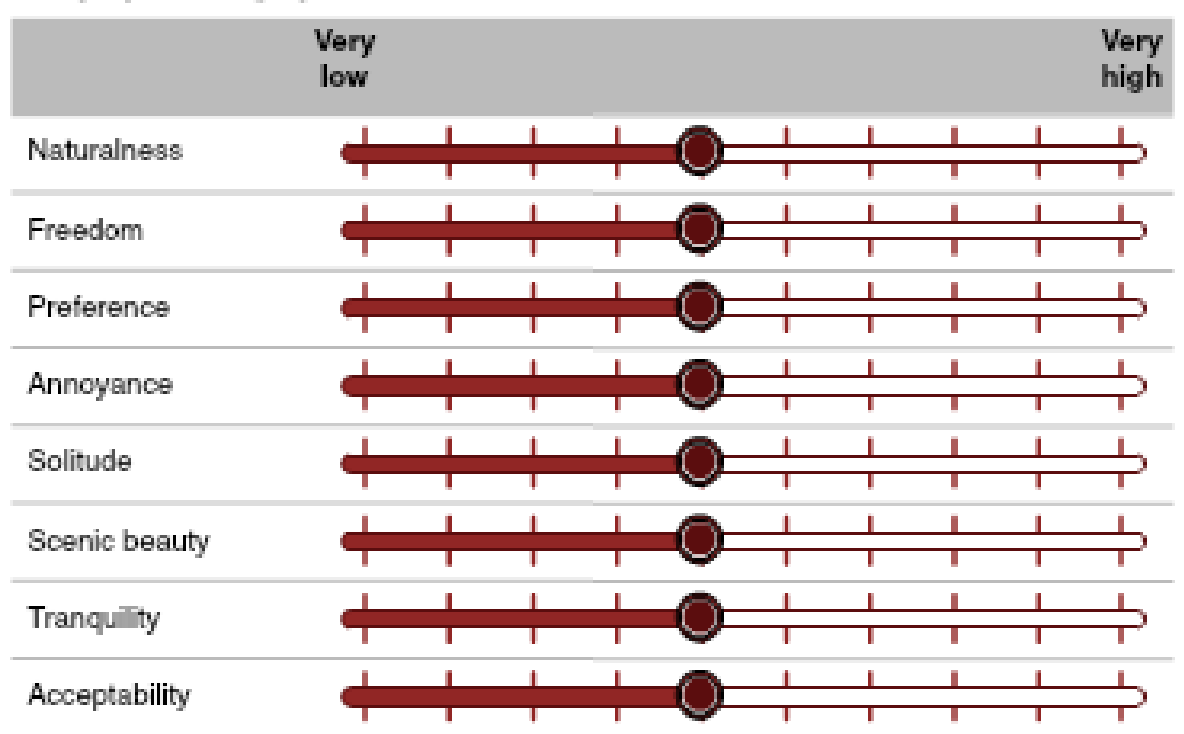

\section{(3\%) ColoradoStateUniversity}

Figure A-2 (continued). Landscape assessment and attitude questionnaires. 


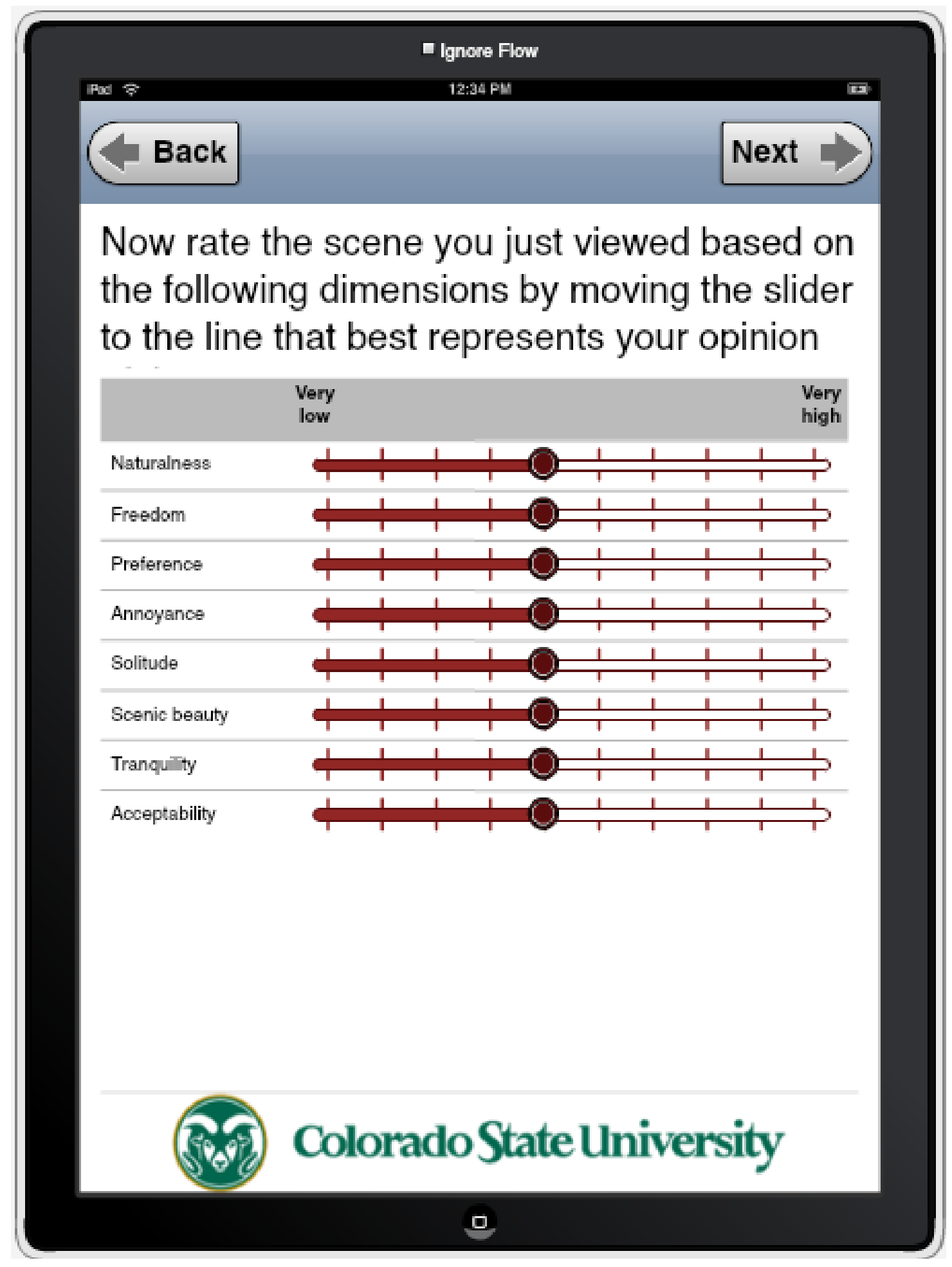

Figure A-2 (continued). Landscape assessment and attitude questionnaires. 


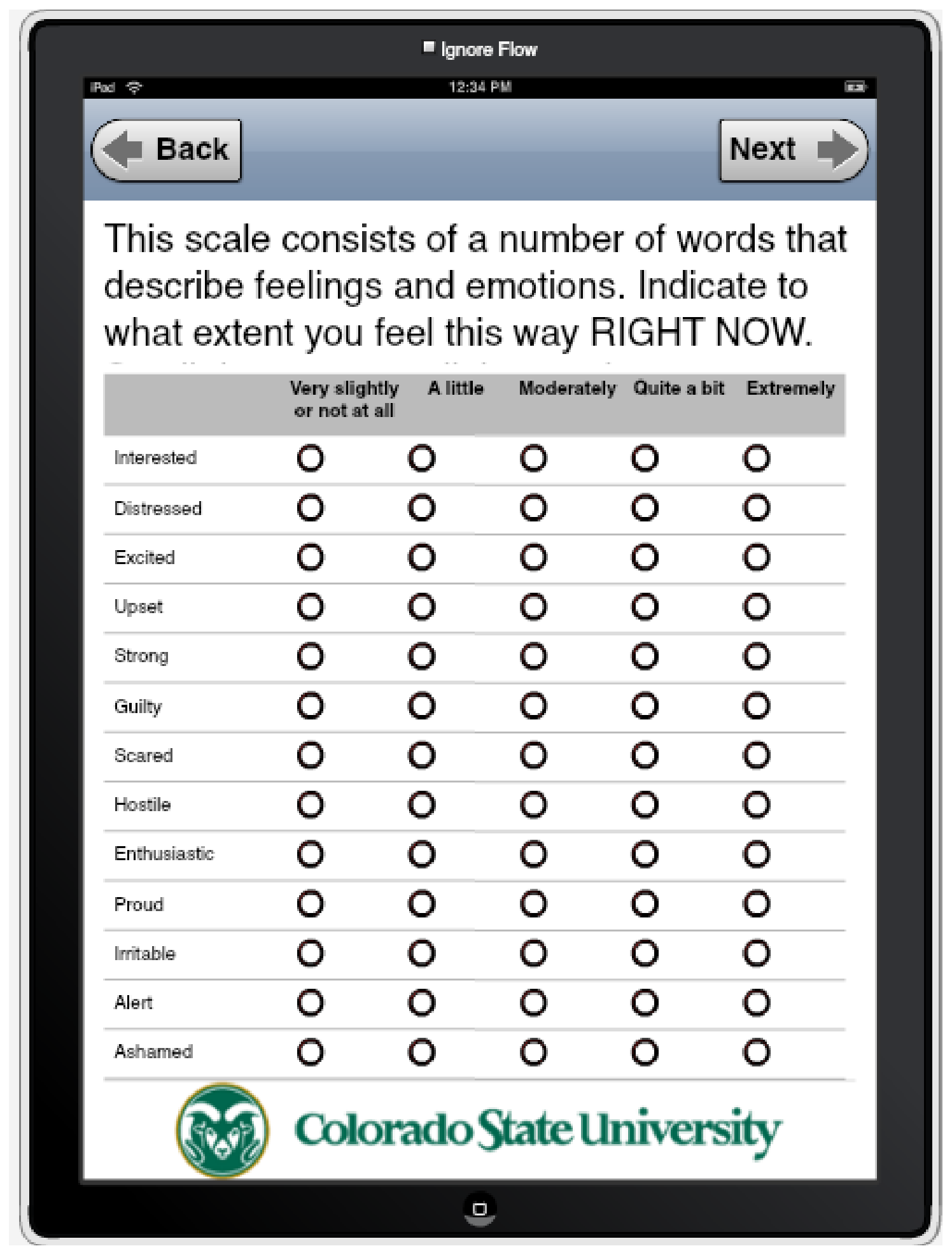

Figure A-2 (continued). Landscape assessment and attitude questionnaires. 


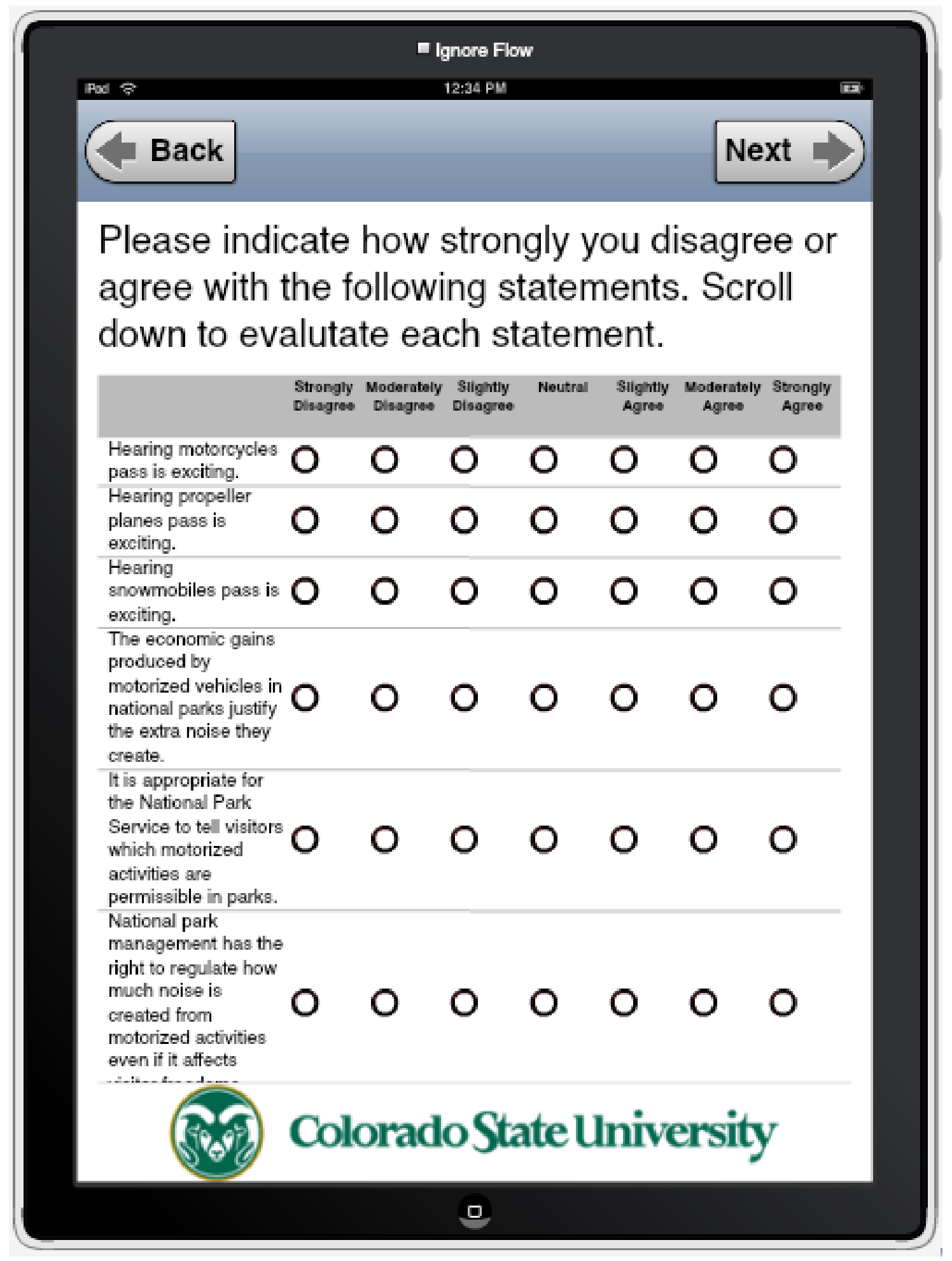

Figure A-2 (continued). Landscape assessment and attitude questionnaires. 


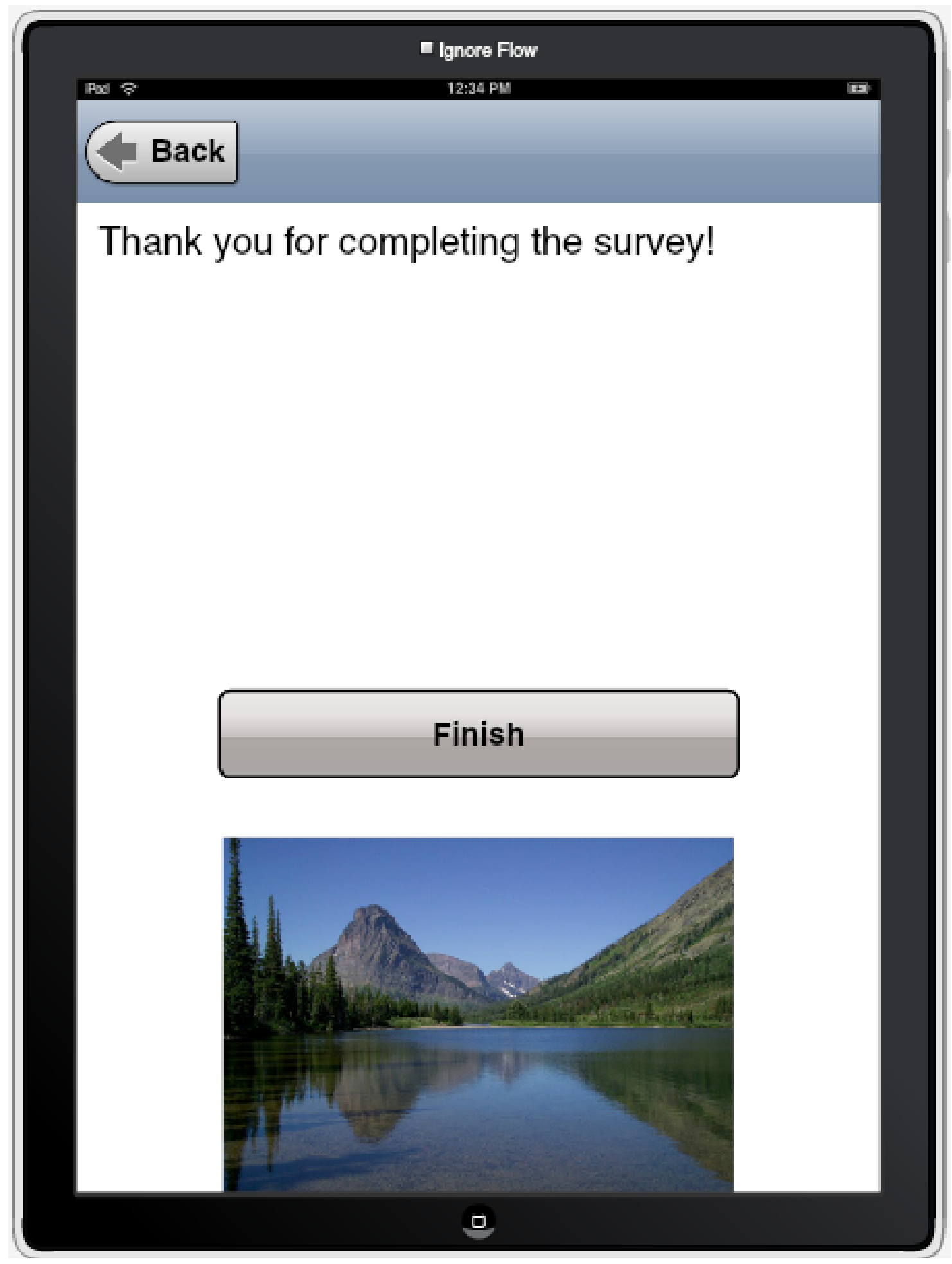

Figure A-2 (continued). Landscape assessment and attitude questionnaires. 